\title{
JAK inhibition reduces SARS-CoV-2 liver infectivity and modulates inflammatory responses to reduce morbidity and mortality
}

\begin{abstract}
Justin Stebbing ${ }^{1+*}$, Ginés Sánchez Nievas ${ }^{2 \dagger}$, Marco Falcone ${ }^{3 \dagger}$, Sonia Youhanna ${ }^{4 \dagger}$, Peter Richardson ${ }^{5}$, Silvia $^{4}$ Ottaviani $^{1}$, Joanne X. Shen ${ }^{4}$, Christian Sommerauer ${ }^{6}$, Giusy Tiseo ${ }^{3}$, Lorenzo Ghiadoni ${ }^{3}$, Agostino Virdis ${ }^{3}$, Fabio Monzani $^{3}$, Luis Romero Rizos ${ }^{7,8}$, Francesco Forfori ${ }^{9}$, Almudena Avendaño-Céspedes ${ }^{7,8}$, Salvatore De Marco $^{10}$, Laura Carrozzi ${ }^{9}$, Fabio Lena ${ }^{11}$, Pedro Manuel Sánchez-Jurado ${ }^{7,8}$, Leonardo Gianluca Lacerenza ${ }^{11}$, Nencioni Cesira $^{12}$, David Caldevilla-Bernardo ${ }^{13}$, Antonio Perrella ${ }^{12}$, Laura Niccoli ${ }^{14}$, Lourdes Sáez Méndez ${ }^{15}$, Daniela Matarrese $^{16}$, Delia Goletti ${ }^{17}$, Yee-Joo Tan $^{18}$, Vanessa Monteil ${ }^{19}$, George Dranitsaris ${ }^{20}$, Fabrizio Cantini $^{14}$, Alessio Farcomeni $^{21}$, Shuchismita Dutta ${ }^{22}$, Stephen K. Burley ${ }^{22}$, Haibo Zhang ${ }^{23}$, Mauro Pistello ${ }^{24}$, William Li ${ }^{25}$, Marta Mas Romero $^{7}$, Fernando Andrés Pretel ${ }^{26}$, Rafaela Sánchez Simón-Talero ${ }^{27}$, Rafael García-Molina ${ }^{7}$, Claudia $^{2}$ Kutter $^{6}$, James H. Felce ${ }^{28}$, Zehra F. Nizami ${ }^{28}$, Andras G. Miklosii ${ }^{28}$, Josef M. Penninger ${ }^{29,30}$,Francesco Menichetti $^{3 *}$, Ali Mirazimi ${ }^{18 *}$, Pedro Abizanda ${ }^{7,8 *}$ and Volker M. Lauschke ${ }^{4 * *}$
\end{abstract}

\begin{abstract}
${ }^{1}$ Department of Surgery and Cancer, Imperial College, London, UK. 'Department of Rheumatology, Complejo Hospitalario Universitario de Albacete, Albacete, Spain. ${ }^{3}$ Department of Clinical and Experimental Medicine, University of Pisa, Italy. ${ }^{4}$ Department of Physiology and Pharmacology, Karolinska Institutet, Stockholm, Sweden. ${ }^{5}$ BenevolentAI, Maple Street, London, UK. ${ }^{6}$ Department of Microbiology, Tumor, and Cell Biology, Karolinska Institute, Science for Life Laboratory, Solna, Sweden. ${ }^{7}$ Department of Geriatric Medicine, Complejo Hospitalario Universitario de Albacete, Albacete, Spain. ${ }^{8}$ CIBERFES, Ministerio de Economía y Competitividad, Spain. ${ }^{9}$ Department of Surgical, Medical and Molecular Pathology and Critical Care Medicine, University of Pisa, Italy. ${ }^{10}$ Department of Internal Medicine, Azienda Ospedaliera Universitaria Pisana, Italy. ${ }^{11}$ Department of Pharmaceutical Medicine, Misericordia Hospital, Grosseto, Italy. ${ }^{12}$ Department of Medicine, Misericordia Hospital, Grosseto, Italy. ${ }^{13}$ Department of Radiology, Complejo Hospitalario Universitario de Albacete, Albacete, Spain. ${ }^{14}$ Department of Rheumatology, Hospital of Prato, Italy. ${ }^{15}$ Department of Internal Medicine, Complejo Hospitalario Universitario de Albacete, Albacete, Spain. ${ }^{16}$ Hospital network ASL Toscana Centro, Toscana, Italy. ${ }^{17}$ Department of Epidemiology and Preclinical Research, National Institute for Infectious Diseases - IRCCS, Rome, Italy. ${ }^{18 K a r o l i n s k a ~ I n s t i t u t e, ~ D e p a r t m e n t ~ o f ~ L a b o r a t o r y ~ M e d i c i n e, ~ U n i t ~ o f ~ C l i n i c a l ~}$ Microbiology, Stockholm, Sweden and National Veterinary Institute, Uppsala, Sweden. ${ }^{19}$ Department of Laboratory Medicine, Karolinska Institutet, Stockholm, Sweden. ${ }^{20}$ Department of Hematology, School of Medicine, University of loannina, Greece. ${ }^{21}$ Department of Economics and Finance, University of Rome Tor Vergata, Rome Italy. ${ }^{22}$ RCSB Protein Data Bank, Rutgers, The State University of New Jersey, Piscataway, USA. ${ }^{23}$ Department of Anesthesia, Medicine and Physiology, University of Toronto, Canada. ${ }^{24}$ Virology Unit, Department of Translational Research, University of Pisa, Italy. ${ }^{25}$ The Angiogenesis Foundation, Cambridge, Massachusetts, USA. ${ }^{26}$ Department of Statistics, Complejo Hospitalario Universitario de Albacete, Albacete, Spain. ${ }^{27}$ Department of Pneumology, Complejo Hospitalario Universitario de Albacete, Albacete, Spain. ${ }^{28}$ Oxford Nanoimaging, Oxford, UK. ${ }^{29}$ Institute of Molecular Biotechnology of the Austrian Academy of Sciences, Vienna, Austria. ${ }^{30}$ Department of Medical Genetics, Life Science Institute, University of British Columbia, Vancouver, Canada

†These authors contributed equally to this work.
\end{abstract}

$\ddagger$ These authors contributed equally to this work.

*Corresponding author. Email: j.stebbing@imperial.ac.uk (J.S.) and volker.lauschke@ki.se (V.M.L.)

Using Al we identified baricitinib as possessing anti-viral and anti-cytokine efficacy. We now show a $71 \%$ $(95 \% \mathrm{Cl} 0.15-0.58)$ mortality benefit in 83 patients with moderate-severe SARS-CoV-2 pneumonia with few drug-induced adverse events, including a large elderly cohort (median age 81 years). A further 48 cases with mild-moderate pneumonia recovered uneventfully. Using organotypic 3D cultures of primary human liver cells, we demonstrate that interferon-alpha-2 (IFN 2 2) significantly increases ACE2 expression and SARS-CoV-2 infectivity in parenchymal cells by $>5$-fold. RNA-Seq reveals gene response signatures associated with platelet activation, fully inhibited by baricitinib. Using viral load quantifications and superresolution microscopy, baricitinib exerts activity rapidly through the inhibition of host proteins (numb associated kinases), uniquely amongst anti-virals. This reveals mechanistic actions of a Janus kinase-1/2 inhibitor targeting viral entry, replication and the cytokine storm, and is associated with beneficial outcomes including in severely ill elderly patients, data that incentivizes further randomized controlled trials.

\section{Introduction}

The novel severe acute respiratory syndrome coronavirus 2 (SARS-CoV-2) pandemic has become the biggest public health challenge of this century with more than 1 million fatalities and 34 million cases of coronavirus disease 2019 (COVID-19) across all countries in the first 10 months since it 
emerged (1-4). It is essential that more effective treatments are found before a vaccine is developed and made widely available $(5,6)$. We previously reported that use of AI based on a knowledge graph of over 1 billion relationship edges enabled the rapid identification of the once daily orally administered drug, baricitinib, approved as a treatment for adult rheumatoid arthritis (RA), as a potential therapeutic (711). Baricitinib was predicted to have a dual mode of action, reducing viral infectivity through the inhibition of numbassociated kinases (NAKs) and thus viral endocytosis, and its better known well-described anti-inflammatory mechanism through blockade of JAK1/2 (12-14).

In severe cases, the so-called 'cytokine storm' can result in profound lung damage and the development of acute respiratory distress syndrome (ARDS), the leading cause of death in COVID-19 $(15,16)$. SARS-CoV-2 infection also results in damage to many other organs including the kidneys, brain and vasculature via mechanisms including endothelial cell disruption and intussusceptive angiogenesis (17, 18). Plasma levels of the pro-inflammatory cytokine interleukin-6 (IL-6) signaling predominantly through JAK/STAT, have been reported to be a prognostic indicator of mortality $(19,20)$ and using samples from a randomized phase-2b trial in RA (4) we demonstrated that baricitinib reduces IL- 6 levels in a dosedependent manner (21), the first time this has been shown in patients. Therapeutics capable of clearing the virus and reducing the cytokine-mediated inflammation may be beneficial. Purported anti-viral agents have at best a small impact on disease remission in hospitalized patients, and in some cases show no differences in viral loads compared to control arms (22). Dexamethasone, known to modulate inflammation-mediated lung injury, resulted in lower mortality among those who were receiving either invasive mechanical ventilation or oxygen alone at randomization (23). In many cases, patients are unable to withstand the exuberant inflammation associated with ARDS, or because high viral loads also cause disseminated end-organ compromise through vascular endothelitis, thrombotic, and other associated effects $(24,25)$.

In this situation, an assessment of the efficacy of baricitinib would include demonstration of reduced viral infectivity and associated end-organ damage, and control of the excessive cytokine-mediated inflammation. Here, we explore the clinical effect of baricitinib therapy patients and matched controls from two European cohorts. Since COVID-19 is associated with multi-system organ damage we also investigated whether the cytokine mediated inflammation could induce the expression of the SARS-CoV-2 receptor ACE2 $(26,27)$ in extra-pulmonary systems. We show that type-1 interferons, specifically IFN $\alpha 2$, whose levels are increased in patients with severe COVID-19 (28), increase ACE2 expression in 3D cultures of primary human liver cells, resulting in increased viral load, and that this induction is fully inhibited by clinically relevant concentrations of baricitinib.

\section{Results \\ Clinical results}

A total of 601 patients were enrolled at the University of Pisa $(n=179)$ and Albacete Hospital $(n=422)$ cohorts, between midMarch and mid-April 2020, when these regions were the global epicenters of the pandemic, under severe capacity constraints. Of these, 37 patients were treated with baricitinib in the Pisa cohort, and 46 in the Albacete cohort all of European descent; 83 controls were included using propensity score matching systems, both in the Italian and in the Spanish cohorts, as per the CONSORT diagram (Fig. 1).

Tables 1 and 2 present baseline data of participants from Pisa and Albacete, respectively, showing clinical characteristics immediately following admission, and Table 3 propensity score matched populations data from both sites, comprising the group taking baricitinib and the control group. Male sex was predominant, and the Albacete patients were older than those from Pisa (80.9 vs. 66.0 years) in treated groups. Most individuals received concomitant 'antiviral therapy' with hydroxychloroquine and lopinavir/ritonavir, antibiotics, corticosteroids and LMWH. In the merged matched population, the primary composite-endpoint of death or invasive mechanical ventilation occurred in $14(16.9 \%)$ patients in the baricitinib-treated group compared to $29(34.9 \%)$ in the control group $(p<0.001)$ (Table 3 ). In the multivariate Cox-regression analysis adjusted for all the covariates included in the matching of the two cohorts, baricitinib was independently associated as a protective variable with the primary outcome (HR 0.29; 95\% CI 0.15-0.58; $p<0.001$ ) (Table 4). Figure 2 presents the Kaplan-Meier curves for the primary outcome in the treated and control groups in the merged cohorts. Baricitinib's favorable effect appeared 'early' and was maintained until termination of the follow-up $(p<0.0001)$. Further analyses including only participants who received 5 or more baricitinib doses yielded similar results as those presented. Analyses of the propensity score matched cohorts from the University of Pisa (Figure S3A) and Albacete Hospital (Figure S3B) are shown independently. Similar curves and statistics can be observed, compared with the final merged cohort (Fig. 2).

\section{Safety issues with baricitinib}

A major role of observational studies is to provide relevant information regarding toxicity. Seven (19\%) individuals from Pisa reported a transaminitis (2-5x upper limit of normal, ULN) within 72 hours of commencing baricitinib leading to cessation of the drug in four of these patients. In three patients and in our previous published small series (21) we continued to treat despite this, and the liver function abnormalities self-resolved. One patient developed a severe 
lymphocytopenia ( $<500$ cells $/ \mathrm{mm}^{3}$ ) during treatment leading to drug discontinuation. A total of 5 (14\%) individuals from Pisa developed infectious complications during baricitinib treatment as follows: one bacteremia due to E. faecalis arising from the urinary tract, two episodes of central venous catheter (CVC)-related bacteremia due to coagulase negative Staphylococci, one urinary-tract infection by NDM-producing Klebsiella pneumoniae, and one severe facial herpes simplex infection. In the unmatched control group, a total of 21 (14.8\%) patients developed an infection: 8 bloodstream infections, 8 urinary tract infections and 5 with pneumonia. In the PS-matched control group, 6 (16.2\%) episodes of infection occurred: one bacteremia due to $E$. aerogenes arising from the urinary tract, one bacteremia by NDM-producing Klebsiella pneumoniae, 3 urinary tract infections (due to E. coli, E. faecalis and Klebsiella pneumoniae), and one pneumonia by Pseudomonas aeruginosa.

Apart from transaminitis, adverse events were difficult to ascribe to baricitinib due to rapidly evolving clinical/capacity constraints. We did not observe any signs of coagulopathy or thrombosis caused by baricitinib in any of our patients, though this has been described as a potential toxicity associated with longer term use in RA (12-14). However, the majority were anti-coagulated with LMWH.

In the Spanish cohort, a transaminitis of 2x ULN was observed after baricitinib treatment in 8 (17\%) patients and at $3 \mathrm{x}$ ULN in 4 (9\%) patients; the drug was not stopped in any individual based on this and abnormalities normalized despite the continuation of treatment. Other adverse events probably or possibly related to baricitinib were observed in 9 (20\%) patients: 2 oral candidiasis, 1 bacteremia for Enterococcus faecium, one bacterial pneumonia with negative cultures, 3 new atrial fibrillation (all had previous heart disease), 1 hypertensive episode, 1 episode of heart failure in the presence of known heart disease, 1 case of urinary obstruction, 1 episode of diarrhea, and 1 gastrointestinal bleed in an individual with gastric malignancy. In the unmatched control group from Albacete $(\mathrm{n}=376)$, we observed $17(4.5 \%)$ urinary tract infections and one Herpes Zoster reactivation. Other complications were gastrointestinal (nausea, vomiting or diarrhea) in $30.7 \%$, hepatic in $4.5 \%$, renal in $21.1 \%$, neurologic in $9.8 \%$, cutaneous in $4 \%$ and arrhythmias in $5.1 \%$.

\section{Interferons sensitize 3D primary human liver cultures to $S A R S-C o V-2$ infections by inducing $A C E 2$}

Organotypic 3D cultures of primary human liver cells are susceptible to infection with SARS-CoV-2 as previously reported (21), with virus signals being enriched in proximity to ACE2 proteins (Fig. 3A). Thus, we evaluated the effect(s) of cytokines on ACE2 expression. To evaluate cytokine effects on human liver cells, we focused on interferons (IFN- $\alpha 2$, IFN- $\beta$ and IFN- $\gamma$ ), interleukins (IL-1 $\beta$, IL6, IL10 and IL18) and $\mathrm{TNF} \alpha$, serum levels of which are increased in patients with moderate-to-severe disease $(15,16,29)$. We detected $>5$-fold induction of ACE2 expression after $16 \mathrm{~h}$ of exposure with IFN- $\alpha 2$ and IFN- $\beta$, whereas IFN- $\gamma, \mathrm{TNF} \alpha$ and the other interleukins tested did not induced ACE2 in liver microtissues (Fig. 3B). As IFN- $\alpha 2$ serum levels in patients exceed those of IFN- $\beta$, we focused our subsequent analyses on IFN- $\alpha 2$. Co-exposure of liver spheroids to IFN- $\alpha 2$ in combination with other cytokines did not significantly amplify IFN-mediated ACE2 induction (Fig. 3C). Based on these data we thus hypothesized that increased levels of IFN- $\alpha 2$ in patients with severe SARSCoV-2 infection can stimulate ACE2 expression in parenchymal cells and further increase virulence.

Next, we evaluated the effects of IFN- $\alpha 2$ mediated induction of ACE2 on viral load and found that IFN- $\alpha 2$ increased viral copy numbers in 3D organotypic liver cultures by approximately 2 -fold (Fig. 3D). Importantly, exposure to therapeutically relevant concentrations of baricitinib (800 nM) fully abolished ACE2 induction by IFN- $\alpha 2$ and efficiently blocked the increased infectivity in cytokine treated 3D liver microtissues even beyond the levels observed in non-cytokine exposed samples (Fig. 3D, E), in agreement with our previous report (21). In contrast, in lung organoids, IFN- $\alpha 2$ did not induce ACE2 even at higher concentrations and had opposite, i.e., mild antiviral, effects (50 ng/ml compared to $10 \mathrm{ng} / \mathrm{ml}$ for liver spheroids; Figs. 3F,G), suggesting that interferon effects differ between pulmonary organs and liver. Furthermore, baricitinib did not reduce viral levels in monkey kidney epithelial cells (Vero cells) and human adenocarcinomic alveolar basal epithelial cells (A549 cells) (Figure S4). These results demonstrate that infection and replication mechanisms in primary cells and cell lines are distinctly different and incentivize the use of organotypic culture systems for studies of infectious disease biology.

\section{Baricitinib efficiently blocks interferon signaling}

To gain detailed understanding of the molecular effects of baricitinib, we sequenced primary liver spheroids using RNASeq, resulting in the first comprehensive map of IFNresponse genes in human hepatocytes. In infected and noninfected liver spheroids, IFN $\alpha 2$ significantly induced a total of 407 and 696 genes, respectively (log2 fold-change $(\mathrm{FC})>|1|$ and false discovery rate (FDR) $<0.05$; Fig. 4A). Genes that were differentially expressed irrespective of infection $(n=271)$ were strongly enriched in viral defense pathways, antigen presentation and endosomal trafficking (Fig. 4B). Interestingly, IFN strongly regulated genes associated with platelet activation (30), but this effect was blunted by viral infection, demonstrating intricate pathway-specific fine-tuning of host gene expression by SARS-CoV-2.

Importantly, baricitinib reversed IFN-induced gene expression changes (Fig. 4C). Genes that were highly induced 
upon IFN treatment were significantly down-regulated by baricitinib, including the IFN-stimulated genes (ISG) 15 and 20, chemokines (CCL8 and CXCL10), MHC components (CD74, LAG3 and LAMP3), and several members of the interferon induced protein (IFIT) family. In contrast, baricitinib reverses the IFN-mediated inhibition of immunoreceptor signaling (SYK), metabolic remodelers (BCAT1 and KSR2) and transcriptional regulators (SOX4 and TLE2; Fig. 4D, E). The only genes that escaped baricitinib action were serum amyloid A1 (SAA1) and its paralogue SAA2, whose expression levels were decreased upon IFN treatment and even further reduced upon baricitinib.

\section{Baricitinib binds to host numb associated kinases}

Ligand binding studies as carried out by Sorrell et al. (31) documented that all three of these closely related enzymes are effectively inhibited by baricitinib (BIKE $\mathrm{K}_{\mathrm{d}}=39.8 \mathrm{nM}$; AAK1 $\mathrm{K}_{\mathrm{d}}=17.2 \mathrm{nM}$; GAK $\mathrm{K}_{\mathrm{d}}=134.4 \mathrm{nM}$ ) (Figures S1, S2). While the most relevant NAK in the inhibition of viral entry is unclear, BIKE was not expressed in liver cells suggesting that AAK1 and/or GAK are sufficient to mediate viral entry. To disentangle the effects of baricitinib on replication and viral entry, we evaluated viral loads $4 \mathrm{~h}$ post infection using baricitinib concentrations close to the relevant $K_{d}$ values (100 nM). dSTORM super-resolution microscopy revealed anti-nucleocapsid protein immunoreactivity clusters throughout the infected samples (Fig. 5A). In contrast, virus signals were almost absent in baricitinib-treated samples (Fig. 5B). The density of anti-nucleocapsid staining in baricitinib-treated spheroids was almost absent and in baricitinib-treated samples $(\mathrm{p}<0.001)$ and reduced to levels found in non-infected controls, demonstrating that baricitinib efficiently blocked viral entry at nanomolar concentrations (Fig. 5C). These results were corroborated by qPCR analyses, which showed significant reductions in intracellular viral loads, irrespective of IFN-mediated ACE2 induction (Fig. 5D). Combined these data corroborate a dual effect model for baricitinib in which the compound i) inhibits the induction of interferon response genes, such as ACE2, resulting in reduced infectivity during the cytokine storm, and ii) blocks viral entry by inhibition of NAKs (Fig. 5E).

Model building was also used to assess the potential impact of selected point mutations that occur with differening frequencies naturally, on baricitinib binding to BIKE (Ala58 $\rightarrow$ Asp, $\quad$ Ala58 $\rightarrow$ Val, $\quad$ Arg134 $\rightarrow$ Gln, $\quad$ Arg134 $\rightarrow$ Leu, Glu131 $\rightarrow$ Gln, Glu131 $\rightarrow$ Lys, Ala135 $\rightarrow$ Thr), and modeled baricitinib binding to both AAK1 (Ala72 $\rightarrow$ Thr, Gly132 $\rightarrow$ Val) and

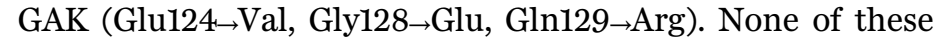
point mutations appear likely to destabilize the structure of the kinase catalytic domain (i.e., disrupt packing in the hydrophobic core). In addition, none of these point mutations appear likely to disrupt baricitinib binding (Table S1). All of the hydrogen bonds and van der Waals interactions observed between the drug and wild-type BIKE appear to be preserved for each point mutant (Figure S2A). The same holds true for the predicted hydrogen bonds and van der Waals interactions between the drug and mutant forms of AAK1 (Figure S2B) and the drug and mutant forms of GAK (Figure S2C), respectively.

\section{Discussion}

Effective and well-tolerated treatments for patients infected with the novel coronavirus have proved elusive. Here, we link antiviral and anti-cytokine activities of baricitinib in hospitalized patients with COVID-19 pneumonia and in spheroid models of SARS-CoV-2 infection. During the pandemic's exponential phase, in investigator-led studies in both Italy and Spain, the treatment of hospitalized patients with COVID-19 using the JAK/STAT pathway inhibitor baricitinib is associated with clinical improvement, findings that require assessment in randomized trials (32). The inclusion of a large cohort with a median age of 81 years merits particular attention here.

Baricitinib was generally well tolerated with a reduction in inflammation and substantially improved outcomes. In the matched populations, $16.9 \%$ of the baricitinib treated patients died and/or progressed to invasive mechanical ventilation, compared to $34.9 \%$ in the standard of care group $(p<0.001$; Fig. 2). It is noteworthy that baricitinib's effects were evident from the first treatment days, and maintained over follow-up (Fig. 2). Although most recommended treatment regimens support the use of $4 \mathrm{mg}$ for 14 days, lower doses and shorter durations may be beneficial for certain populations including elderly patients described here. It is also remarkable from our data that in the propensity score matched populations from both sites, most of the participants received similar treatment regimens with hydroxychloroquine, lopinavir/ritonavir, LMWH and glucocorticoids. In Cox proportional hazard analyses, these treatments did not affect survival, while baricitinib was beneficial in univariate, multivariate, and time-related analyses (Table 4).

The main toxicities observed were hepatic, infectious, gastrointestinal and cardiovascular, although in most cases a definite causative relationship with baricitinib use could not be ascertained. An elevation in plasma transaminases occurred in some patients and as previously observed, continuation of baricitinib was possible with resolution of liver function abnormalities. A recent case report in an 87-year-old severely unwell patient from Foggia, Italy, showed its use was associated with rapid clinical improvement in stark contrast to her infected husband and son who did not receive baricitinib and died (33). While such reports are inconclusive, in aggregate these data strongly support the continued investigation of baricitinib for COVID-19 in ongoing randomized 
control trials, including ACTT-II (NCT04401579), where baricitinib is given in combination with remdesivir, TACTIC-R (NCT04390464) and others including NCT04373044. Multivariate analyses we performed showed no differences in corticosteroid type (prednisolone, dexamethasone, hydrocortisone or methylprednisolone), duration, dose and outcome.

Age appears the most relevant risk factor for adverse outcomes related to COVID-19 (16). In patients with COVID-19 pneumonia, immune dysfunction is present, even in mild cases (26), and immune responses in older adults are slower, less coordinated, and less efficient, so-called immunosenescence (34). Until now, there have been no clinical trials or post-authorization studies that have demonstrated efficacy or safety of commonly used drugs in much older adults hospitalized with COVID-19, an especially vulnerable and susceptible population, and age is often an exclusion criteria in trials, as is frailty.

One concern in early disease is amelioration of the antiviral activity of type-1 IFNs, which signal through JAK/STAT pathways. Our study using viral infection assays in liver spheroids confirms that ACE2 is an interferon stimulated gene, supporting previous data (35). This induction should increase viral infectivity rather than reduce it. Interestingly, this was observed in human hepatocytes which normally express low levels of this receptor, in contrast to endothelial cells where ACE2 is abundantly expressed and contributes to the local control of perfusion. This in turn suggests that extra-pulmonary effects of COVID-19 may be mediated by type-1 IFNmediated increases in ACE2 expression, both on endothelial and parenchymal cells, resulting in endotheliitis (25) and liver injury in up to $60 \%$ of severely ill patients (36). While deficiency in type I IFN immunity is associated with lifethreatening COVID-19 pneumonia (37), induction of IFNs and IFN-stimulated genes is detected in some critically ill patients (38). In aggregate with our findings in liver spheroids, these data suggest that type I IFNs play an important bivalent role in COVID pathobiology that requires tight regulation and lead us to hypothesize that JAK/STAT inhibitors could be beneficial early in the course of the disease by reducing IFN-I induced ACE2 expression. Notably, we found important qualitative differences between the response of liver spheroids, where IFNs induced ACE2 and increased infectivity, and lung organoids, where ACE2 and viral load was not affected by IFN signaling. Vascular endothelial cells express high levels of ACE2 (39); however, while endothelial cells are highly responsive to IFN signaling (40), whether ACE2 constitutes an IFN response gene remains to be elucidated. Combined, these data suggest that the effects of baricitinib might differ between organ systems and we could speculate that the anti-inflammatory effects might be most beneficial in those tissues in which ACE2 is an IFN response gene, including liver. It will be interesting to see if further systematic analyses of the effect of IFNs on ACE2 expression and infectivity across human tissues will confirm these hypotheses.

To further validate our data in early patients and strengthen the safety database, we also present results for a further 48 patients with mild-moderate pneumonia treated at 2 hospitals in Italy (Table 5 and Table S1); a transient transaminitis was observed in 2 individuals and all patients recovered uneventfully, the commonest drug induced adverse event in 131 baricitinib-treated individuals presented here.

The susceptibility of liver spheroids to SARS-CoV2 infection was at first surprising to us, but ties in with the transaminitis observed. It is notable that SARS-CoV-2 can productively infect human gut enterocytes as shown using human small intestinal organoids (41). We have analyzed ACE2 expression in available proteomics and RNA-Seq data and detected low level ACE2 transcripts or protein with average FPKM data across three donors of 0.95 (42). These levels are consistent with previous data indicating low but detectable levels of ACE2 in liver cells (43). We have also interrogated the TCGA with the UALCAN database and found low levels of ACE2 transcripts in peritumoral liver cells in hepatocellular carcinoma data.

The demonstration that baricitinib inhibited viral infectivity in vitro, as well as having an overall anti-inflammatory effect in vivo, confirms predictions arising from the use of AI and the comprehensive biomedical knowledge graph (7-9). Importantly, it also demonstrates that compiling such an AI enriched database, with its associated algorithms, enables the identification of relationships, in this case the ability of a single approved drug to both inhibit viral infectivity and ameliorate the exuberant inflammatory consequences of viral infection. It also enables network effects to be identified quickly, of enormous importance when trying to identify therapeutics in the midst of a global pandemic (10).

We did not observe any thrombotic or vascular events in our cohort, a previously raised possible concern with the use of baricitinib and also an increasing concern in general with COVID-19 infection $(14,44,45)$, although most patients (86\%) here received LMWH. The short half-life of baricitinib $(\mathrm{t} 1 / 2=12.5$ hours $)$ versus the anti-IL- 6 antibodies such as tocilizumab ( $t=13$ days), oral once/daily administration and lack of drug-drug interactions (it is excreted largely unchanged) we believe lend itself to use during a short-term viral infection and also the possibility of utility in low and middle-income countries. A glomerular filtration rate (GFR) $<30$ $\mathrm{mL} / \mathrm{min}$ is a limitation for the higher $4 \mathrm{mg}$ dose but a $2 \mathrm{mg}$ dose can be used: we highlight from the Spanish cohort that specifically shows that baricitinib may be safe and effective with the lower $2 \mathrm{mg}$ dose and fewer treatment days. Randomized trials are needed in this elderly population and note for example that many other studies (e.g., for remdesevir) 
exclude elderly individuals or those with a GFR $<50 \mathrm{~mL} / \mathrm{min}$. Other features such as its potential to cross the blood brain barrier and help ameliorate neurologic sequelae may also be beneficial in selected patients, as we have described $(46,47)$. Trials of other JAK inhibitors such as ruxolitinib are ongoing and the same principles may apply (48), although our knowledge graph specifically called out baricitinib amongst these related molecules (9). Interestingly, we noted the brain:plasma ratio for baricitinib measured $5 \mathrm{x}$ that for ruxolitinib (46). Further, the computational docking results (Figures S3, S4) suggest that any one, or 2, or all 3 of the NAKs could be the baricitinb target(s) relevant to our clinical findings, although BIKE is unexpressed on liver spheroids so the target is likely to be AAK1 and/or GAK. We consider it unlikely that baricitinib is acting on an alternative protein target(s) that may not even be a protein kinase, but cannot rule out this possibility. For example, TMPRSS2, a membranebound serine protease that primes the spike protein (49), is also well known to be important for viral entry via ACE2. IL6 signaling (50) is related to its expression and baricitinib, which reduces IL-6 levels in a dose-dependent manner, may affect its expression. Should additional clinical studies confirm the benefits of baracitinib in managing advanced SARSCoV-2 infections, efforts aimed at identification of the precise molecular target(s) would be useful here.

Notwithstanding our findings supporting the hypothesis that baricitinib is clinically active and safe in this setting, there are several limitations in our study that need to be acknowledged. This was not a randomized trial comparing baricitinib to a placebo control group. Therefore, known, and unknown confounding variables could have compromised the results. The PS-matching procedure eliminated much of the group imbalance in known confounding variables but some imbalance remained in important parameters such as existing comorbidities. In addition, the sample size from the final baricitinib cohort was small, limiting overall statistical power. Multiple statistical tests were performed without an adjustment for multiplicity, which increases the risk of a type-I statistical error. Given these limitations, we eagerly await the completion of the baricitinib randomized trials that are currently ongoing.

In summary we have confirmed dual actions of baricitinib, demonstrating its ability to inhibit viral entry into primary human hepatocyte spheroids and the reduction in inflammatory markers in COVID-19 patients as per our suggested model (Fig. 5C). In addition, we show that baricitinib prevents the type-1 IFN mediated increase in the expression of ACE2, the receptor for SARS-CoV-2.

\section{Materials and Methods Patients and statistics}

Two observational studies from Italy and Spain were conducted, approved by the Internal Review Boards (IRBs) of each institution. Entry criteria for each institution, included patients with radiologically defined COVID-19 pneumonia and laboratory confirmed infection, as diagnosed by a positive SARS-CoV-2 RT-PCR test by nasopharyngeal swab. All patients enrolled had an $\mathrm{SaO}_{2}<94 \%$ at baseline but did not require mechanical ventilation. The Pisa, Italy, cohort included all consecutive cases with SARS-CoV-2 pneumonia and $\mathrm{PO}_{2} / \mathrm{FiO}_{2}(\mathrm{P} / \mathrm{F})$ ratio $<300 \mathrm{mmHg}$ at admission diagnosed between the period of $7^{\text {th }}$ and $31^{\text {st }}$ March 2020, and had moderate-to-severe or severe disease. The COVID-AGE study from Albacete, Spain (NCT04362943), was conducted at Complejo Hospitalario Universitario of Albacete, dedicated to older adults, thus baricitinib doses were lower than in Italy. The Albacete cohort included patients $\geq 70$ years with SARS-CoV2 pneumonia, diagnosed between $9^{\text {th }}$ March and $20^{\text {st }}$ April 2020 , not requiring mechanical ventilation, and again having moderate-to-severe or severe disease.

Written informed consent was obtained from each patient in Italy, and verbal informed consent in Spain as approved by the local IRB. Baricitinib was administered at a dose of 4 $\mathrm{mg} /$ day for 14 days in conjunction with standard of care in Italy, and at lower doses of 2 or $4 \mathrm{mg} /$ day for 3 to 11 days in the Spanish cohort because of age-related factors. Any patient with confirmed COVID-19 infection who received at least 3 doses of baricitinib was included in the intent-to-treat analysis. Standard clinical and laboratory data were collected including patients' demographics, co-morbidities, oxygensupport, adverse events, laboratory values, concomitant therapies, and clinical outcomes. Exclusion criteria in all patients included a history of active or latent tuberculosis infection (QuantiFERON Plus-test positivity, Qiagen, Germany), pregnancy and/or lactation. The primary outcome was death from any cause or Intensive Care Unit (ICU) admission needing invasive mechanical ventilation during hospitalization.

For both cohorts, propensity score matching was utilized to create the control selection sample using patients admitted in the same period of time in both hospitals, not treated with baricitinib. Cases and controls were matched for relevant predictors of respiratory failure and death, as well as baseline treatments. The following variables, all of them clinically relevant for mortality and respiratory failure, were included in the propensity score estimation: age, sex, chronic obstructive pulmonary disease (COPD), arterial hypertension, cardiovascular disease, diabetes mellitus, chronic kidney failure, Charlson comorbidity index, baseline $\mathrm{P} / \mathrm{F}$ ratio, lymphocyte count, therapy with steroids, low molecular weight heparin (LMWH), and 'anti-viral' therapy with hydroxychloroquine or protease inhibitors (lopinavir/ritonavir). Propensity score matching was conducted with the statistical package «MatchIt» (v4.0.2), using the recommendations from Ho D.E. et al. (51) to improve parametric models and pre-processing 
of non-parametric data. After the propensity score was determined for each patient, those treated with baricitinib were matched to $1: 1$ to a control patient using a greedy matching procedure with replacement, targeting the Average Treatment effect on the Treated. replacement. Continuous variables were tested using Wilcoxon-Mann-Whitney rank sum test; categorical variables were tested using Pearson's chi square or Fisher's exact test. For every test performed the $p$ value was always above 0.05 and therefore we can say that the groups where homogeneous regarding the control variables. Validity of the balance in potential confounding variables was assessed visually with normality plots using the " $R$ " function ['geom_smooth()' using formula 'y $\mathrm{x}$ '], also using the Wilkcoxon rank sum test with continuity correction analyses for continuous variables, and with Pearson's chi square tests for categorical ones. Although the matching figures were not perfect, no statistical differences were found for any variables included in the propensity score in the merged Pisa and Albacete cohorts. Mortality reduction was analyzed with Cox proportional hazard models adjusted for all the variables included in the propensity score matching, to further control for the small deviations in the matching procedure, plus the presence of active cancer, alanine aminotransferase (ALT) and antibiotic use. Safety data are presented in a descriptive manner. Finally, individual and merged data from Pisa and Albacete were used to analyze the primary outcome, survival or mechanical ventilation, in baricitinib and control groups using Kaplan-Meier analysis, including 95\% confidence intervals. The global significance was determined using a PetoPeto analysis that priorizes the first part of the curves but with increased robustness compared to Taron-Ware analysis. This decision was taken after the observation that the main differences between baricitinib and control patients were present from the beginning of the treatment. Statistical significance was established at $p<0.05$ using a two-sided test statistic. All analyses were done using the statistical package "R".

\section{Human spheroid and organoid culture, cytokine expo- sures and SARS-CoV-2 infections}

SARS-CoV-2 (GenBank accession number MT093571) was isolated from a nasopharyngeal sample of a patient in Sweden on Vero E6 cells. Organotypic 3D primary human liver cultures with physiological transcriptomic, proteomic and metabolomic profiles were cultured as previously described (52-54). In short, cryopreserved PHH (BioIVT, USA) were thawed and the isolated cell suspensions were seeded into 96well ultra-low attachment plates (Corning) with 1,500 cells per well. In short, cells were seeded in $100 \mu \mathrm{l}$ Williams E medium supplemented with $2 \mathrm{mM}$ L-glutamine, 100 units $/ \mathrm{ml}$ penicillin, $100 \mu \mathrm{g} / \mathrm{ml}$ streptomycin, $10 \mu \mathrm{g} / \mathrm{ml}$ insulin, 5.5 $\mu \mathrm{g} / \mathrm{ml}$ transferrin, $6.7 \mathrm{ng} / \mathrm{ml}$ sodium selenite, $100 \mathrm{nM}$ dexamethasone, and 10\% FBS. Spontaneous self-aggregation of the hepatocytes occurred and after few days a single spheroid could be observed per well. Once spheroids were sufficiently compact (after day 5), cell aggregates were preexposed to baricitinib and/or cytokines.

Formed liver spheroids and pulmonary organoids were exposed for 1 day with reconstituted human IFN $\alpha 2$ (Biolegend; \#592706), IFN $\beta$ (R\&D Systems; \#8499-IF-010), IFNץ (Biolegend; \#570206), IL1 $\beta$ (Biolegend; \#579406), IL6 (R\&D Systems; \#206-IL-050), IL10 (R\&D Systems; \#217-IL-010), IL18 (Biolegend; \#592104) and TNF $\propto$ (R\&D Systems; \#210-TA100) either alone or in combination with baricitinib before viral infections. Cytokine concentrations were $10 \mathrm{ng} / \mathrm{ml}$ unless stated otherwise. Following these pre-exposures, cells were infected with SARS-CoV2 at a multiplicity of infection of 0.1 in triplicate for 48 hours. After 48 hours, spheroids were washed with PBS, pooled (32 wells/condition) and lyzed using TrizolTM (Thermofisher). RNA was extracted using Direct-zol mini-kit (Zymo-research) and relative levels of ACE2 and viral RNA were determined by qRT-PCR as described (55).

\section{Confocal microscopy}

Primary human hepatocyte spheroids were fixed in $4 \%$ paraformaldehyde for at least $4 \mathrm{~h}$ and washed with PBS. For cryoprotection spheroids were incubated with $30 \%$ sucrose in PBS at $4{ }^{\circ} \mathrm{C}$ overnight or until the microtissues sank. Subsequently, they were washed with PBS and transferred into micro molds for OCT cryo-mount embedding. OCT-embedded spheroids were frozen in an isopropanol dry ice bath and were sectioned at $8 \mu \mathrm{m}$ thickness on a CryoStar NX70 Cryostat. Sections were washed twice with PBS for $10 \mathrm{~min}$ and blocked with PBTA buffer (5\% BSA, 0.25\% Triton X-100, $0.01 \%$ NaN3 in PBS) for two hours at room temperature. Subsequently, the blocked sections were incubated overnight at $4^{\circ} \mathrm{C}$ with the monoclonal primary antibody anti-1A9 (diluted in PBTA to a final concentration $5 \mu \mathrm{g} / \mathrm{ml}$ ). Samples were washed 3x15 min with PBS at room temperature before incubation with the secondary antibody (donkey anti-mouse diluted in PBTA 1:500) for 2 hours at room temperature. Unbound secondary antibody was washed out three times with PBS (15 min each) at room temperature and the slides were mounted with DAPI Gold anti-fade.

\section{Super-resolution microscopy}

Sections, prepared as above, were thawed and rehydrated using PBS then blocked for 30 min using a blocking buffer containing $10 \%$ goat serum, $2 \%$ BSA and $0.3 \%$ triton X. Primary antibody against nucleocapsid was diluted 1:500 in 10\% goat serum and $2 \% \mathrm{BSA}$ and incubated overnight at $4^{\circ} \mathrm{C}$. Sections were then washed with PBS 3x10 min. Primary antibodies were detected with alexa fluor-647 conjugated secondary 
goat-anti mouse $\mathrm{F}\left(\mathrm{ab}^{\prime}\right) 2$ (abcam; ab98758) diluted to 500 $\mathrm{ng} / \mathrm{ml}$ in $10 \%$ goat serum and $2 \%$ BSA for 1 hour at room temperature. Finally, sections were washed $5 \times 10 \mathrm{~min}$ and mounted using ONI B-Cubed imaging buffer. Super-resolution images were acquired on the Nanoimager S Mark II from ONI (Oxford Nanoimaging) equipped with $405 \mathrm{~nm} / 150 \mathrm{~mW}$, $473 \mathrm{~nm} / 1 \mathrm{~W}, 560 \mathrm{~nm} / 1 \mathrm{~W}, 640 \mathrm{~nm} / 1 \mathrm{~W}$ lasers and dual emission channels split at $640 \mathrm{~nm}$. To achieve single molecule blinking, samples were irradiated with the 640 lased then 10000 frames were acquired in an appropriate focal plane at $30 \mathrm{~Hz}$. Single molecule data was filtered based on photon count, precision and sigma value in NimOS. All samples were filtered using the same parameters.

\section{$\boldsymbol{R N A}-\mathrm{Seq}$}

RNA was isolated from 3D liver tissue samples and were ribosomal RNA depleted, followed by strand-specific RNA library generation (Takara Smart-Seq stranded kit). RNA libraries were sequenced paired end $(75+75$ cycles $)$ on an Illumina NextSeq 500 device. On average 20 million reads per sample were obtained and low quality reads were removed and ends were trimmed using Trimmomatic (version 0.36). Ribosomal RNA (rRNA) contamination was determined by mapping to a customized human rRNA reference genome (HISAT2 version 2.1.0). Approximately, 8-15\% rRNA contamination was found in the samples, which is below the manufacturer's expected range between 15 and $35 \%$. Non-aligned reads were further mapped to the human reference genome (downloaded from UCSC, hg38). After mapping to the human genome, generated .bam files were processed using samtools (version 1.10). Bedgraph files were generated using Homer (version 4.11). Finally, count tables were generated using the tool SubRead (version 2.0.0).

Differential gene expression (DEG) analysis was performed using both DESeq2 (version 1.26) and edgeR (version 3.28). For both methods, genes with zero counts were filtered out and more than 8 counts in at least 2 of the 12 samples were considered further. In DESeq2, independent filtering and Cook's distance were set to false. In edgeR, the glmLRT method was used. Only genes with $\log 2$ fold-change $(\mathrm{FC})>|1|$ and false discovery rate (FDR) $<0.05$ were considered. When intersecting the number of differentially expressed genes identified using the two methods, we found an overlap of $>90 \%$ and continued the analysis by using the data obtained from DESeq2. Pathway analysis was performed using the $\mathrm{R}$ package ReactomePA (version 1.30.0).

\section{Computational structure analysis}

Three-dimensional (3D) atomic-level structures of NAKs BIKE (PDB ID 4w9x), AAK1 (PDB ID 4wsq), and GAK (PDB ID 4y8d were compared at the level of amino acid sequence and 3D structure (Figures S1, S2). Superposition computational docking using the experimental structure of the BIKE-baricitinib protein:drug complex (PDB ID 4w9x) was used to investigate the modes of binding of baricitinib to both AAK1 and GAK (Figure S2). Figures were generated using UCSF Chimera (56).

\section{REFERENCES AND NOTES}

1. A. S. Fauci, H. C. Lane, R. R. Redfield, Covid-19 - Navigating the Uncharted. N. Engl. J. Med. 382, 1268-1269 (2020). doi:10.1056/NEJMe2002387 Medline

2. C. I. Paules, H. D. Marston, A. S. Fauci, Coronavirus Infections-More Than Just the Common Cold. JAMA 323, 707-708 (2020). doi:10.1001/jama.2020.0757 Medline

3. Z. Wu, J. M. McGoogan, Characteristics of and Important Lessons From the Coronavirus Disease, 2019 (COVID-19) Outbreak in China: Summary of a Report of 72314 Cases From the Chinese Center for Disease Control and Prevention. JAMA 323, 1239-1242 (2020). doi:10.1001/jama.2020.2648 Medline

4. Y. Tanaka, K. Emoto, Z. Cai, T. Aoki, D. Schlichting, T. Rooney, W. Macias, Efficacy and Safety of Baricitinib in Japanese Patients with Active Rheumatoid Arthritis Receiving Background Methotrexate Therapy: A 12-week, Double-blind, Randomized Placebo-controlled Study. J. Rheumatol. 43, 504-511 (2016). doi:10.3899/irheum.150613 Medline

5. L. R. Baden, E. J. Rubin, Covid-19 - The Search for Effective Therapy. N. Engl. J. Med. 382, 1851-1852 (2020). doi:10.1056/NEJMe2005477 Medline

6. A. Mullard, COVID-19 vaccine development pipeline gears up. Lancet 395, 17511752 (2020). doi:10.1016/S0140-6736(20)31252-6 Medline

7. P. Richardson, I. Griffin, C. Tucker, D. Smith, O. Oechsle, A. Phelan, M. Rawling, E. Savory, J. Stebbing, Baricitinib as potential treatment for 2019-nCoV acute respiratory disease. Lancet 395, e30-e31 (2020). doi:10.1016/S01406736(20)30304-4 Medline

8. P. J. Richardson, M. Corbellino, J. Stebbing, Baricitinib for COVID-19: A suitable treatment? - Authors' reply. Lancet Infect. Dis. 20, 1013-1014 (2020). doi:10.1016/S1473-3099(20)30270-X Medline

9. J. Stebbing, V. Krishnan, S. de Bono, S. Ottaviani, G. Casalini, P. J. Richardson, V. Monteil, V. M. Lauschke, A. Mirazimi, S. Youhanna, Y.-J. Tan, F. Baldanti, A. Sarasini, J. A. R. Terres, B. J. Nickoloff, R. E. Higgs, G. Rocha, N. L. Byers, D. E. Schlichting, A. Nirula, A. Cardoso, M. Corbellino; Sacco Baricitinib Study Group, Mechanism of baricitinib supports artificial intelligence-predicted testing in COVID-19 patients. EMBO Mol. Med. 12, el2697 (2020). doi:10.15252/emmm.202012697 Medline

10. M. B. Schultz, D. Vera, D. A. Sinclair, Can artificial intelligence identify effective COVID-19 therapies? EMBO Mol. Med. 12, e12817 (2020) doi:10.15252/emmm.202012817 Medline

11. B. K. Titanji, M. M. Farley, A. Mehta, R. Connor-Schuler, A. Moanna, S. K. Cribbs, J. O'Shea, K. DeSilva, B. Chan, A. Edwards, C. Gavegnano, R. F. Schinazi, V. C. Marconi, Use of Baricitinib in Patients with Moderate and Severe COVID-19. Clin. Infect. Dis. ciaa879 (2020). Medline

12. J. S. Fridman, P. A. Scherle, R. Collins, T. C. Burn, Y. Li, J. Li, M. B. Covington, B. Thomas, P. Collier, M. F. Favata, X. Wen, J. Shi, R. McGee, P. J. Haley, S. Shepard, J. D. Rodgers, S. Yeleswaram, G. Hollis, R. C. Newton, B. Metcalf, S. M. Friedman, K. Vaddi, Selective inhibition of JAK1 and JAK2 is efficacious in rodent models of arthritis: Preclinical characterization of INCB028050. J. Immunol. 184, 52985307 (2010). doi:10.4049/jimmunol.0902819 Medline

13. M. C. Genovese, J. Kremer, O. Zamani, C. Ludivico, M. Krogulec, L. Xie, S. D. Beattie, A. E. Koch, T. E. Cardillo, T. P. Rooney, W. L. Macias, S. de Bono, D. E. Schlichting, J. S. Smolen, Baricitinib in Patients with Refractory Rheumatoid Arthritis. N. Engl. J. Med. 374, 1243-1252 (2016). doi:10.1056/NEJMoa1507247 Medline

14. P. C. Taylor, E. C. Keystone, D. van der Heijde, M. E. Weinblatt, L. Del Carmen Morales, J. Reyes Gonzaga, S. Yakushin, T. Ishii, K. Emoto, S. Beattie, V. Arora, C. Gaich, T. Rooney, D. Schlichting, W. L. Macias, S. de Bono, Y. Tanaka, Baricitinib versus Placebo or Adalimumab in Rheumatoid Arthritis. N. Engl. J. Med. 376, 652662 (2017). doi:10.1056/NEJMoa1608345 Medline

15. C. Huang, Y. Wang, X. Li, L. Ren, J. Zhao, Y. Hu, L. Zhang, G. Fan, J. Xu, X. Gu, Z. Cheng, T. Yu, J. Xia, Y. Wei, W. Wu, X. Xie, W. Yin, H. Li, M. Liu, Y. Xiao, H. Gao, L. Guo, J. Xie, G. Wang, R. Jiang, Z. Gao, Q. Jin, J. Wang, B. Cao, Clinical features of 
patients infected with 2019 novel coronavirus in Wuhan, China. Lancet 395, 497506 (2020). doi:10.1016/S0140-6736(20)30183-5 Medline

16. F. Zhou, T. Yu, R. Du, G. Fan, Y. Liu, Z. Liu, J. Xiang, Y. Wang, B. Song, X. Gu, L. Guan, Y. Wei, H. Li, X. Wu, J. Xu, S. Tu, Y. Zhang, H. Chen, B. Cao, Clinical course and risk factors for mortality of adult inpatients with COVID-19 in Wuhan, China: A retrospective cohort study. Lancet 395, 1054-1062 (2020). doi:10.1016/S01406736(20)30566-3 Medline

17. M. Ackermann, S. E. Verleden, M. Kuehnel, A. Haverich, T. Welte, F. Laenger, A. Vanstapel, C. Werlein, H. Stark, A. Tzankov, W. W. Li, V. W. Li, S. J. Mentzer, D. Jonigk, Pulmonary Vascular Endothelialitis, Thrombosis, and Angiogenesis in Covid-19. N. Engl. J. Med. 383, 120-128 (2020). doi:10.1056/NEJMoa2015432 Medline

18. O. Gross, O. Moerer, M. Weber, T. B. Huber, S. Scheithauer, COVID-19-associated nephritis: Early warning for disease severity and complications? Lancet 395, e87e88 (2020). doi:10.1016/S0140-6736(20)31041-2 Medline

19. F. Liu, L. Li, M. Xu, J. Wu, D. Luo, Y. Zhu, B. Li, X. Song, X. Zhou, Prognostic value of interleukin-6, C-reactive protein, and procalcitonin in patients with COVID-19. J. Clin. Virol. 127, 104370 (2020). doi:10.1016/i.jcv.2020.104370 Medline

20. Q. Ruan, K. Yang, W. Wang, L. Jiang, J. Song, Clinical predictors of mortality due to COVID-19 based on an analysis of data of 150 patients from Wuhan, China. Intensive Care Med. 46, 846-848 (2020). Medline

21. J. Stebbing, A. Phelan, I. Griffin, C. Tucker, O. Oechsle, D. Smith, P. Richardson, COVID-19: Combining antiviral and anti-inflammatory treatments. Lancet Infect. Dis. 20, 400-402 (2020). doi:10.1016/S1473-3099(20)30132-8 Medline

22. Y. Wang, D. Zhang, G. Du, R. Du, J. Zhao, Y. Jin, S. Fu, L. Gao, Z. Cheng, Q. Lu, Y. Hu, G. Luo, K. Wang, Y. Lu, H. Li, S. Wang, S. Ruan, C. Yang, C. Mei, Y. Wang, D. Ding, F. Wu, X. Tang, X. Ye, Y. Ye, B. Liu, J. Yang, W. Yin, A. Wang, G. Fan, F. Zhou, Z. Liu, X. Gu, J. Xu, L. Shang, Y. Zhang, L. Cao, T. Guo, Y. Wan, H. Qin, Y. Jiang, T. Jaki, F. G. Hayden, P. W. Horby, B. Cao, C. Wang, Remdesivir in adults with severe COVID-19: A randomised, double-blind, placebo-controlled, multicentre trial. Lancet 395, 1569-1578 (2020). doi:10.1016/S0140-6736(20)31022-9 Medline

23. P. Horby, W. S. Lim, J. R. Emberson, M. Mafham, J. L. Bell, L. Linsell, N. Staplin, C. Brightling, A. Ustianowski, E. Elmahi, B. Prudon, C. Green, T. Felton, D. Chadwick, K. Rege, C. Fegan, L. C. Chappell, S. N. Faust, T. Jaki, K. Jeffery, A. Montgomery, K. Rowan, E. Juszczak, J. K. Baillie, R. Haynes, M. J. Landray; RECOVERY Collaborative Group, Dexamethasone in Hospitalized Patients with Covid-19 Preliminary Report. N. Engl. J. Med. (2020). Medline

24. M. Ackermann, S. E. Verleden, M. Kuehnel, A. Haverich, T. Welte, F. Laenger, A Vanstapel, C. Werlein, H. Stark, A. Tzankov, W. W. Li, V. W. Li, S. J. Mentzer, D. Jonigk, Pulmonary Vascular Endothelialitis, Thrombosis, and Angiogenesis in Covid-19. N. Engl. J. Med. 383, 120-128 (2020). doi:10.1056/NEJMoa2015432 Medline

25. Z. Varga, A. J. Flammer, P. Steiger, M. Haberecker, R. Andermatt, A. S. Zinkernagel, M. R. Mehra, R. A. Schuepbach, F. Ruschitzka, H. Moch, Endothelial cell infection and endotheliitis in COVID-19. Lancet 395, 1417-1418 (2020). doi:10.1016/S0140-6736(20)30937-5 Medline

26. W. Li, M. J. Moore, N. Vasilieva, J. Sui, S. K. Wong, M. A. Berne, M. Somasundaran, J. L. Sullivan, K. Luzuriaga, T. C. Greenough, H. Choe, M. Farzan, Angiotensinconverting enzyme 2 is a functional receptor for the SARS coronavirus. Nature 426, 450-454 (2003). doi:10.1038/nature02145 Medline

27. J. Shang, G. Ye, K. Shi, Y. Wan, C. Luo, H. Aihara, Q. Geng, A. Auerbach, F. Li, Structural basis of receptor recognition by SARS-CoV-2. Nature 581, 221-224 (2020). doi:10.1038/s41586-020-2179-y Medline

28. A. J. Wilk, A. Rustagi, N. Q. Zhao, J. Roque, G. J. Martínez-Colón, J. L. McKechnie, G. T. Ivison, T. Ranganath, R. Vergara, T. Hollis, L. J. Simpson, P. Grant, A. Subramanian, A. J. Rogers, C. A. Blish, A single-cell atlas of the peripheral immune response in patients with severe COVID-19. Nat. Med. 26, 1070-1076 (2020). doi:10.1038/s41591-020-0944-y Medline

29. K. J. Huang, I.-J. Su, M. Theron, Y.-C. Wu, S.-K. Lai, C.-C. Liu, H.-Y. Lei, An interferon-gamma-related cytokine storm in SARS patients. J. Med. Virol. 75, 185194 (2005). doi:10.1002/imv.20255 Medline

30. X. Yang, X. Cheng, Y. Tang, X. Qiu, Z. Wang, G. Fu, J. Wu, H. Kang, J. Wang, H. Wang, F. Chen, X. Xiao, T. R. Billiar, B. Lu, The role of type 1 interferons in coagulation induced by gram-negative bacteria. Blood 135, 1087-1100 (2020). doi:10.1182/blood.2019002282 Medline
31. F. J. Sorrell, M. Szklarz, K. R. Abdul Azeez, J. M. Elkins, S. Knapp, Family-wide Structural Analysis of Human Numb-Associated Protein Kinases. Structure 24, 401-411 (2016). doi:10.1016/i.str.2015.12.015 Medline

32. S. Ottaviani, J. Stebbing, What is the best drug to treat COVID-19? The need for randomized controlled trials. Med, (2020).doi:10.1016/i.medj.2020.04.022.

33. S. Lo Caputo, G. Corso, M. Clerici, T. A. Santantonio, Baricitinib: A chance to treat COVID-19? J. Med. Virol. 92, 2343-2344 (2020). doi:10.1002/imv.26033 Medline

34. J. Nikolich-Zugich et al., SARS-CoV-2 and COVID-19 in older adults: What we may expect regarding pathogenesis, immune responses, and outcomes. Geroscience 42, 405-414 (2020).

35. C. G. K. Ziegler, S. J. Allon, S. K. Nyquist, I. M. Mbano, V. N. Miao, C. N. Tzouanas, Y. Cao, A. S. Yousif, J. Bals, B. M. Hauser, J. Feldman, C. Muus, M. H. Wadsworth 2nd, S. W. Kazer, T. K. Hughes, B. Doran, G. J. Gatter, M. Vukovic, F. Taliaferro, B. E. Mead, Z. Guo, J. P. Wang, D. Gras, M. Plaisant, M. Ansari, I. Angelidis, H. Adler, J. M. S. Sucre, C. J. Taylor, B. Lin, A. Waghray, V. Mitsialis, D. F. Dwyer, K. M. Buchheit, J. A. Boyce, N. A. Barrett, T. M. Laidlaw, S. L. Carroll, L. Colonna, V. Tkachev, C. W. Peterson, A. Yu, H. B. Zheng, H. P. Gideon, C. G. Winchell, P. L. Lin, C. D. Bingle, S. B. Snapper, J. A. Kropski, F. J. Theis, H. B. Schiller, L. E. Zaragosi, P. Barbry, A. Leslie, H. P. Kiem, J. L. Flynn, S. M. Fortune, B. Berger, R. W. Finberg, L. S. Kean, M. Garber, A. G. Schmidt, D. Lingwood, A. K. Shalek, J. OrdovasMontanes; HCA Lung Biological Network. Electronic address: lungnetwork@humancellatlas.org; HCA Lung Biological Network, SARS-CoV-2 Receptor ACE2 Is an Interferon-Stimulated Gene in Human Airway Epithelial Cells and Is Detected in Specific Cell Subsets across Tissues. Cell 181, 1016-1035.e19 (2020). Medline

36. C. Zhang, L. Shi, F. S. Wang, Liver injury in COVID-19: Management and challenges. Lancet 5, 428-430 (2020). Medline

37. Q. Zhang, P. Bastard, Z. Liu, J. Le Pen, M. Moncada-Velez, J. Chen, M. Ogishi, I. K. D. Sabli, S. Hodeib, C. Korol, J. Rosain, K. Bilguvar, J. Ye, A. Bolze, B. Bigio, R. Yang, A. A. Arias, Q. Zhou, Y. Zhang, F. Onodi, S. Korniotis, L. Karpf, Q. Philippot, M. Chbihi, L. Bonnet-Madin, K. Dorgham, N. Smith, W. M. Schneider, B. S. Razooky, H.-H. Hoffmann, E. Michailidis, L. Moens, J. E. Han, L. Lorenzo, L. Bizien, P. Meade, A.-L. Neehus, A. C. Ugurbil, A. Corneau, G. Kerner, P. Zhang, F. Rapaport, Y. Seeleuthner, J. Manry, C. Masson, Y. Schmitt, A. Schlüter, T. Le Voyer, T. Khan, J. Li, J. Fellay, L. Roussel, M. Shahrooei, M. F. Alosaimi, D. Mansouri, H. Al-Saud, F. Al-Mulla, F. Almourfi, S. Z. Al-Muhsen, F. Alsohime, S. Al Turki, R. Hasanato, D. van de Beek, A. Biondi, L. R. Bettini, M. D'Angio', P. Bonfanti, L. Imberti, A. Sottini, S. Paghera, E. Quiros-Roldan, C. Rossi, A. J. Oler, M. F. Tompkins, C. Alba, I. Vandernoot, J.-C. Goffard, G. Smits, I. Migeotte, F. Haerynck, P. Soler-Palacin, A. Martin-Nalda, R. Colobran, P.-E. Morange, S. Keles, F. Çölkesen, T. Ozcelik, K. K. Yasar, S. Senoglu, S.. N. Karabela, C. Rodríguez-Gallego, G. Novelli, S. Hraiech, Y. Tandjaoui-Lambiotte, X. Duval, C. Laouénan, A. L. Snow, C. L. Dalgard, J. D. Milner, D. C. Vinh, T. H. Mogensen, N. Marr, A. N. Spaan, B. Boisson, S. Boisson-Dupuis, J. Bustamante, A. Puel, M. J. Ciancanelli, I. Meyts, T. Maniatis, V. Soumelis, A. Amara, M. Nussenzweig, A. García-Sastre, F. Krammer, A. Pujol, D. Duffy, R. P. Lifton, S.Y. Zhang, G. Gorochov, V. Béziat, E. Jouanguy, V. Sancho-Shimizu, C. M. Rice, L. Abel, L. D. Notarangelo, A. Cobat, H. C. Su, J.-L. Casanova; COVID-STORM Clinicians; COVID Clinicians; Imagine COVID Group; French COVID Cohort Study Group; CoV-Contact Cohort; Amsterdam UMC Covid-19 Biobank; COVID Human Genetic Effort; NIAID-USUHS/TAGC COVID Immunity Group, Inborn errors of type I IFN immunity in patients with life-threatening COVID-19. Science 370, eabd4570 (2020). doi:10.1126/science.abd4570 Medline

38. Z. Zhou, L. Ren, L. Zhang, J. Zhong, Y. Xiao, Z. Jia, L. Guo, J. Yang, C. Wang, S. Jiang, D. Yang, G. Zhang, H. Li, F. Chen, Y. Xu, M. Chen, Z. Gao, J. Yang, J. Dong, B. Liu, X. Zhang, W. Wang, K. He, Q. Jin, M. Li, J. Wang, Heightened Innate Immune Responses in the Respiratory Tract of COVID-19 Patients. Microbe 27, 883890.e2 (2020). Medline

39. I. Hamming, W. Timens, M. L. C. Bulthuis, A. T. Lely, G. Navis, H. van Goor, Tissue distribution of ACE2 protein, the functional receptor for SARS coronavirus. A first step in understanding SARS pathogenesis. J. Pathol. 203, 631-637 (2004). doi:10.1002/path.1570 Medline

40. H. Jia, C. Thelwell, P. Dilger, C. Bird, S. Daniels, M. Wadhwa, Endothelial cell functions impaired by interferon in vitro: Insights into the molecular mechanism of thrombotic microangiopathy associated with interferon therapy. Thromb. Res. 163, 105-116 (2018). doi:10.1016/j,thromres.2018.01.039 Medline 
41. M. M. Lamers, J. Beumer, J. van der Vaart, K. Knoops, J. Puschhof, T. I. Breugem, R. B. G. Ravelli, J. Paul van Schayck, A. Z. Mykytyn, H. Q. Duimel, E. van Donselaar, S. Riesebosch, H. J. H. Kuijpers, D. Schipper, W. J. van de Wetering, M. de Graaf, M. Koopmans, E. Cuppen, P. J. Peters, B. L. Haagmans, H. Clevers, SARS-CoV-2 productively infects human gut enterocytes. Science 369, 50-54 (2020). doi:10.1126/science. abc1669 Medline

42. N. Vilarnau, S. U. Vorrink, M. Ingelman-Sundberg, V. M. Lauschke, A 3D cell culture model identifies Wnt/ $\beta$-catenin mediated inhibition of $\mathrm{p} 53$ as a critical step during human hepatocyte regeneration. Adv. Sci. 7, .. (2020).

43. G. Paizis, C. Tikellis, M. E. Cooper, J. M. Schembri, R. A. Lew, A. I. Smith, T. Shaw, F. J. Warner, A. Zuilli, L. M. Burrell, P. W. Angus, Chronic liver injury in rats and humans upregulates the novel enzyme angiotensin converting enzyme 2. Gut 54 , 1790-1796 (2005). doi:10.1136/gut.2004.062398 Medline

44. M. Levi, J. Thachil, T. Iba, J. H. Levy, Coagulation abnormalities and thrombosis in patients with COVID-19. Lancet Haematol. 7, e438-e440 (2020). doi:10.1016/S2352-3026(20)30145-9 Medline

45. I. C. Scott, S. L. Hider, D. L. Scott, Thromboembolism with Janus Kinase (JAK) Inhibitors for Rheumatoid Arthritis: How Real is the Risk? Drug Saf. 41, 645-653 (2018). doi:10.1007/s40264-018-0651-5 Medline

46. P. J. Richardson, S. Ottaviani, A. Prelle, J. Stebbing, G. Casalini, M. Corbellino, CNS penetration of potential anti-COVID-19 drugs. J. Neurol. 267, 1880-1882 (2020). doi:10.1007/s00415-020-09866-5 Medline

47. C. Gavegnano, W. B. Haile, S. Hurwitz, S. Tao, Y. Jiang, R. F. Schinazi, W. R. Tyor, Baricitinib reverses HIV-associated neurocognitive disorders in a SCID mouse model and reservoir seeding in vitro. J. Neuroinflammation 16, 182 (2019). doi:10.1186/s12974-019-1565-6 Medline

48. J. Zhong, J. Tang, C. Ye, D. L., The immunology of COVID-19: is immune modulation an option for treatment? Lancet Rheumatol, (2020).

49. M. Hoffmann, H. Kleine-Weber, S. Schroeder, N. Krüger, T. Herrler, S. Erichsen, T. S. Schiergens, G. Herrler, N.-H. Wu, A. Nitsche, M. A. Müller, C. Drosten, S. Pöhlmann, SARS-CoV-2 Cell Entry Depends on ACE2 and TMPRSS2 and Is Blocked by a Clinically Proven Protease Inhibitor. Cell 181, 271-280.e8 (2020). doi:10.1016/i.cell.2020.02.052 Medline

50. F. Handle, M. Puhr, G. Schaefer, N. Lorito, J. Hoefer, M. Gruber, F. Guggenberger, F. R. Santer, R. B. Marques, W. M. van Weerden, F. Claessens, H. H. H. Erb, Z. Culig, The STAT3 Inhibitor Galiellalactone Reduces IL6-Mediated AR Activity in Benign and Malignant Prostate Models. Mol. Cancer Ther. 17, 2722-2731 (2018). doi:10.1158/1535-7163.MCT-18-0508 Medline

51. D. E. Ho, K. Imai, G. King, E. A. Stuart, Matching as Nonparametric Preprocessing for Reducing Model Dependence in Parametric Causal Inference. Polit. Anal. 15, 199-236 (2017). doi:10.1093/pan/mpl013

52. C. C. Bell, D. F. G. Hendriks, S. M. L. Moro, E. Ellis, J. Walsh, A. Renblom, L. Fredriksson Puigvert, A. C. A. Dankers, F. Jacobs, J. Snoeys, R. L. Sison-Young, R. E. Jenkins, A. Nordling, S. Mkrtchian, B. K. Park, N. R. Kitteringham, C. E. P. Goldring, V. M. Lauschke, M. Ingelman-Sundberg, Characterization of primary human hepatocyte spheroids as a model system for drug-induced liver injury, liver function and disease. Sci. Rep. 6, 25187 (2016). doi:10.1038/srep25187 Medline

53. C. C. Bell, V. M. Lauschke, S. U. Vorrink, H. Palmgren, R. Duffin, T. B. Andersson, M. Ingelman-Sundberg, Transcriptional, Functional, and Mechanistic Comparisons of Stem Cell-Derived Hepatocytes, HepaRG Cells, and ThreeDimensional Human Hepatocyte Spheroids as Predictive In Vitro Systems for Drug-Induced Liver Injury. Drug Metab. Dispos. 45, 419-429 (2017). doi:10.1124/dmd.116.074369 Medline

54. S. U. Vorrink, S. Ullah, S. Schmidt, J. Nandania, V. Velagapudi, O. Beck, M. Ingelman-Sundberg, V. M. Lauschke, Endogenous and xenobiotic metabolic stability of primary human hepatocytes in long-term 3D spheroid cultures revealed by a combination of targeted and untargeted metabolomics. FASEB J. 31 , 2696-2708 (2017). doi:10.1096/fj.201601375R Medline

55. V. Monteil, H. Kwon, P. Prado, A. Hagelkrüys, R. A. Wimmer, M. Stahl, A. Leopoldi, E. Garreta, C. Hurtado Del Pozo, F. Prosper, J. P. Romero, G. Wirnsberger, H. Zhang, A. S. Slutsky, R. Conder, N. Montserrat, A. Mirazimi, J. M. Penninger, Inhibition of SARS-CoV-2 Infections in Engineered Human Tissues Using ClinicalGrade Soluble Human ACE2. Cell 181, 905-913.e7 (2020). Medline

56. E. F. Pettersen, T. D. Goddard, C. C. Huang, G. S. Couch, D. M. Greenblatt, E. C. Meng, T. E. Ferrin, UCSF Chimera-A visualization system for exploratory research and analysis. J. Comput. Chem. 25, 1605-1612 (2004). doi:10.1002/jcc.20084 Medline

\section{ACKNOWLEDGMENTS}

We are exceedingly grateful to the patients who contributed their data. VML acknowledges support by the Swedish Research Council [grant agreement numbers: 2016-01153, 2016-01154 and 2019-01837], by the Strategic Research Programmes in Diabetes (SFO Diabetes) and Stem Cells and Regenerative Medicine (SFO StratRegen) and the EU/ EFPIA/ OICR/ McGill/KTH/ Diamond Innovative Medicines Initiative 2 Joint Undertaking (EUbOPEN grant 875510). DG is partially funded by Ricerca Corrente Linea 1 and 3 . JS and SO wish to thank the Imperial BRC, ECMC, the NIHR, BSAC and AAC. The RCSB Protein Data Bank is supported by grants to SKB from the National Science Foundation (DBI1832184), the National Institutes of Health (RO1GM133198), and the Department of Energy (DE-SC0019749). PA acknowledges support by CIBERFES, Instituto de Salud Carlos III, Ministerio de Economía y Competitividad, España. Ayuda cofinanciada por el Fondo Europeo de Desarrollo Regional FEDER Una Manera de hacer Europa (Grant number CB16/10/00408). This study was supported by the Imperial BRC and ECMC, the NIHR and AAC. Author contributions: Study concept: JS, FM, AM, PA and VML; clinical data collection: GSN, MF, GT, LG, AV, FM, LRR, FF, AAC, SM, LC, PMS, DCB, LSM, MP, MMR, FAP, RSS, RGM, FM and PA; experimental analyses of liver cultures: SY, JXS and VML; in vitro viral assays: VM, JCS, SY and AM; statistical analyses: GD and PA; super-resolution microscopy: JHF, ZFN and AGM; RNA-Seq: CS and CK; manuscript writing: JS, SY, PA and VML. All authors contributed to data collection and approved the final submitted version. Competing interests: For JS see:

https://www.nature.com/onc/editors (it includes a lecture fee from Eli Lilly for discovering the role of baricitinib here). PR is an employee of BenevolentAl and received an honoraria for a lecture from Eli Lilly for lecturing with JS. MF received grants and speaker honoraria from MSD, Angelini, Shionogi, Nordic Pharma. LG is a co-founder of Quipu, a spin-off company of University of Pisa and National Research Center of Pisa, Italy, received a research grant from Pfizer and speaker honoraria from Boehringer Ingelheim, Corman, Sanofi-Aventis, Sevier. FM has participated in advisory boards and/or received speaker honoraria from Angelini, Correvio, MSD, Pfizer, Astellas, Gilead, BMS, Jansenn, ViiV, BioMerieux, Biotest, Becton-Dickinson, Pfizer, Shionogi. DG has received a research grant from Eli Lilly. SD has no conflicts of interest. SKB received a speaker honorarium from Incyte Pharmaceuticals. VML is founder, CEO and shareholder of HepaPredict AB. In addition, VML discloses consultancy work for EnginZyme AB. GSN has received a speaker honorarium from Eli Lilly. No other authors declare a conflict of interest. Data and materials availability: All data needed to evaluate the conclusions in the paper are present in the paper and/or the Supplementary Materials and Figures.

\section{SUPPLEMENTARY MATERIALS}

advances.sciencemag.org/cgi/content/full/sciadv.abe4724/DC1

Submitted 24 August 2020

Accepted 28 October 2020

Published First Release 13 November 2020

10.1126/sciadv.abe4724 


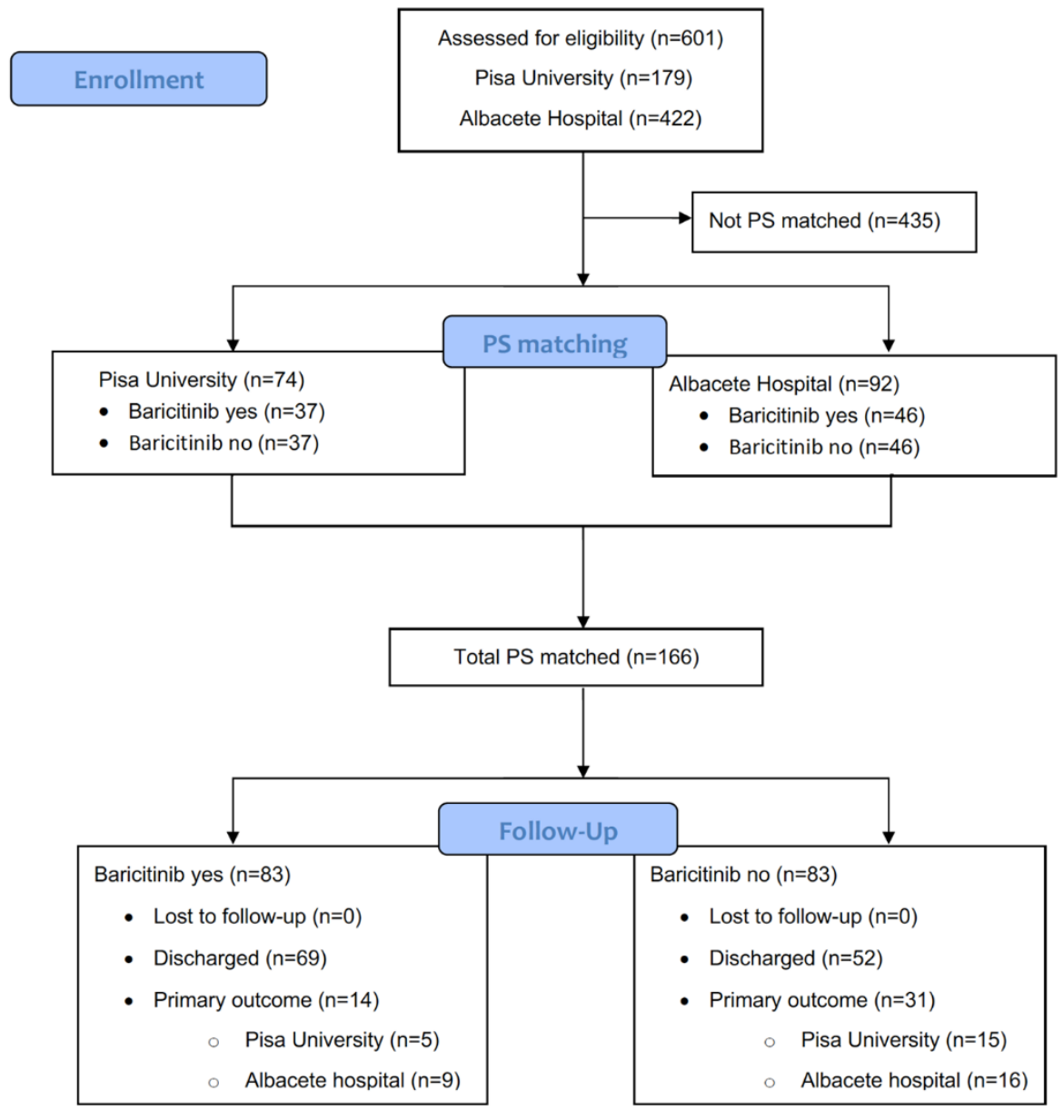

Fig. 1. CONSORT Flow Diagram for Pisa University and Albacete Hospital cohorts. 


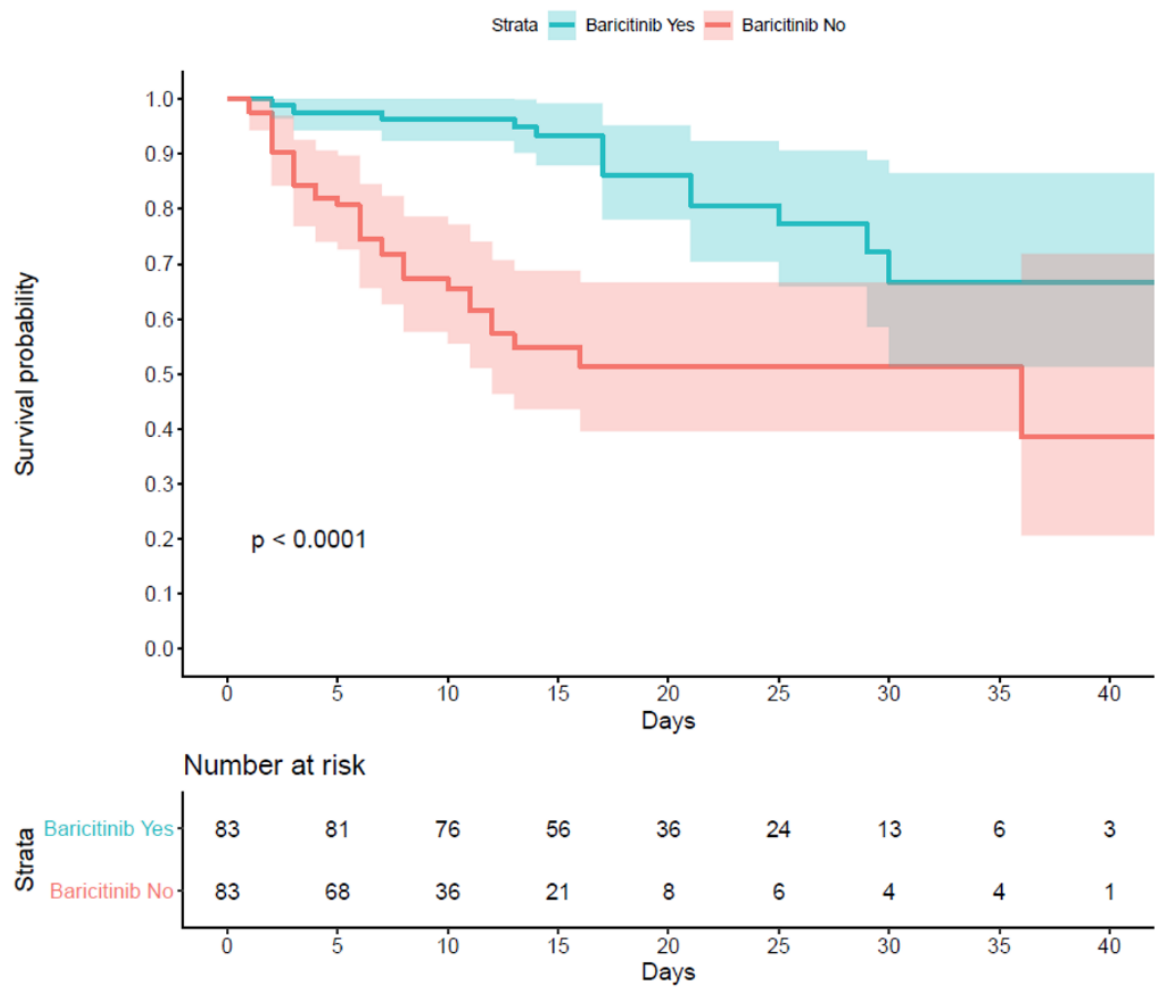

Fig. 2. Kaplan-Meier analysis of the propensity score matched cohorts from Pisa University and Albacete Hospital cohorts. 

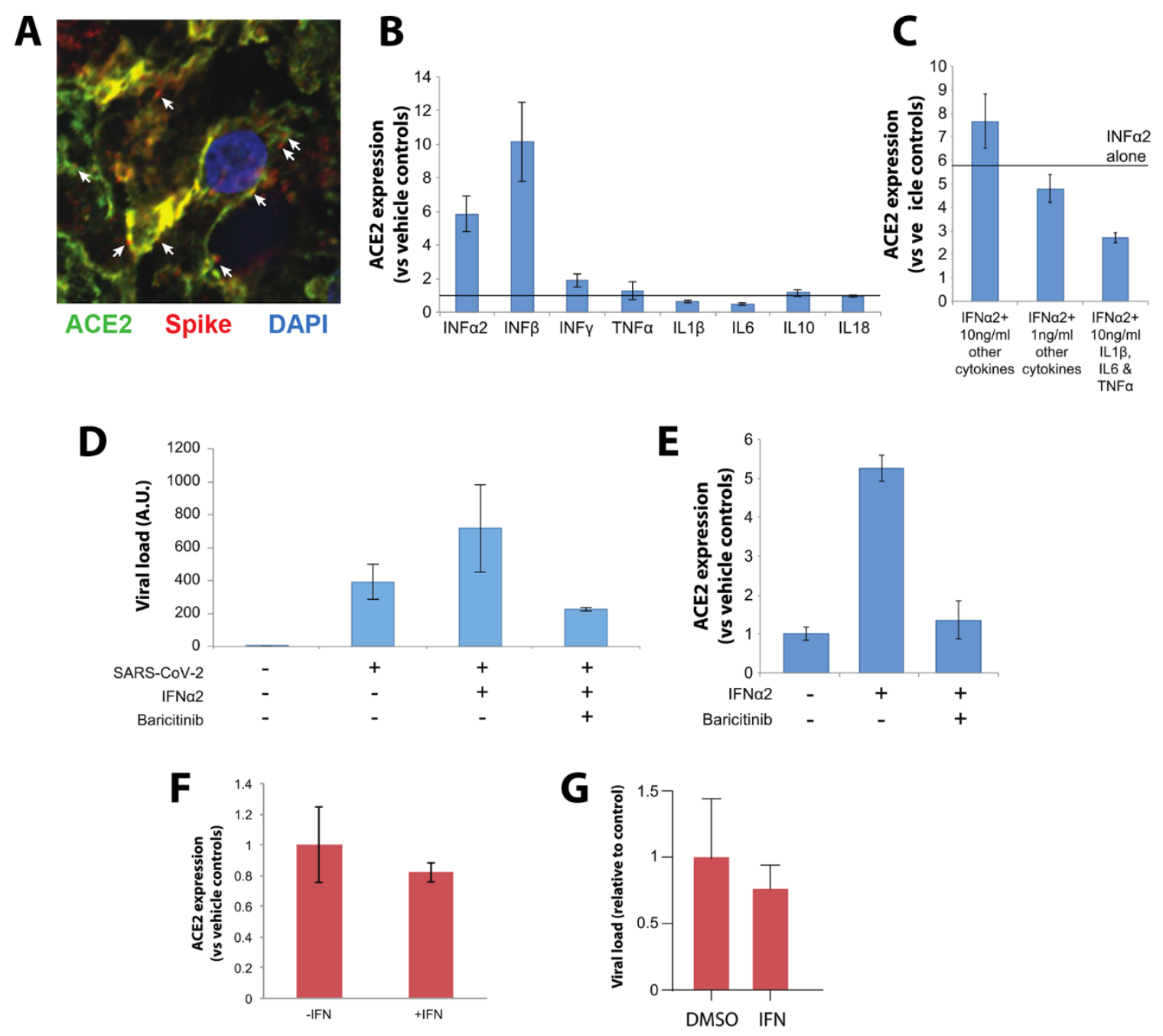

Fig. 3. Baricitinib inhibits cytokine-mediated increased infectivity of SARS-CoV-2 in organotypic primary human liver culture. A, Immunofluorescence confocal imaging of a liver spheroid $48 \mathrm{~h}$ post infection with SARS-CoV-2. Viral spike protein is shown in red, ACE2 in green and DAPI in blue. Arrows indicate examples of where spike protein and ACE2 signals are in close proximity. B, Liver spheroids were treated with $10 \mathrm{ng} / \mathrm{ml}$ of different cytokines and the fold increase in ACE2 transcript levels are shown relative to controls (indicated by dashed line). Note that IFN $\alpha 2$ and IFN $\beta$ significantly induce ACE2 levels. $\mathrm{N}=2$ technical replicates. $\mathrm{C}$, Combinatorial cytokine exposure does not result in increased ACE2 induction compared to IFN $\alpha 2$ alone. "Other cytokines" corresponds to IFN $\beta$, IFN $\gamma$, TNF $\alpha$, IL1 $\beta$, IL6, IL10 and IL18. D, IFNa2 increases viral load in hepatocyte spheroids and this effect is fully inhibited by baricitinib. $\mathrm{N}=2-3$ biological replicates. $\mathrm{E}$, IFN $\alpha 2$ mediated induction of ACE2 is fully prevented by baricitinib. $\mathrm{N}=3$ biological replicates. All cytokine concentrations were $10 \mathrm{ng} / \mathrm{ml}$ unless stated otherwise. F, ACE2 in lung organoids is not induced even by very high concentrations of IFNa2 (50ng/ml). $\mathrm{N}=3$ biological replicates. G, By contrast, IFNa2 slightly reduces viral load in lung organoids. $\mathrm{N}=3$ biological replicates. Error bars indicate SEM. 

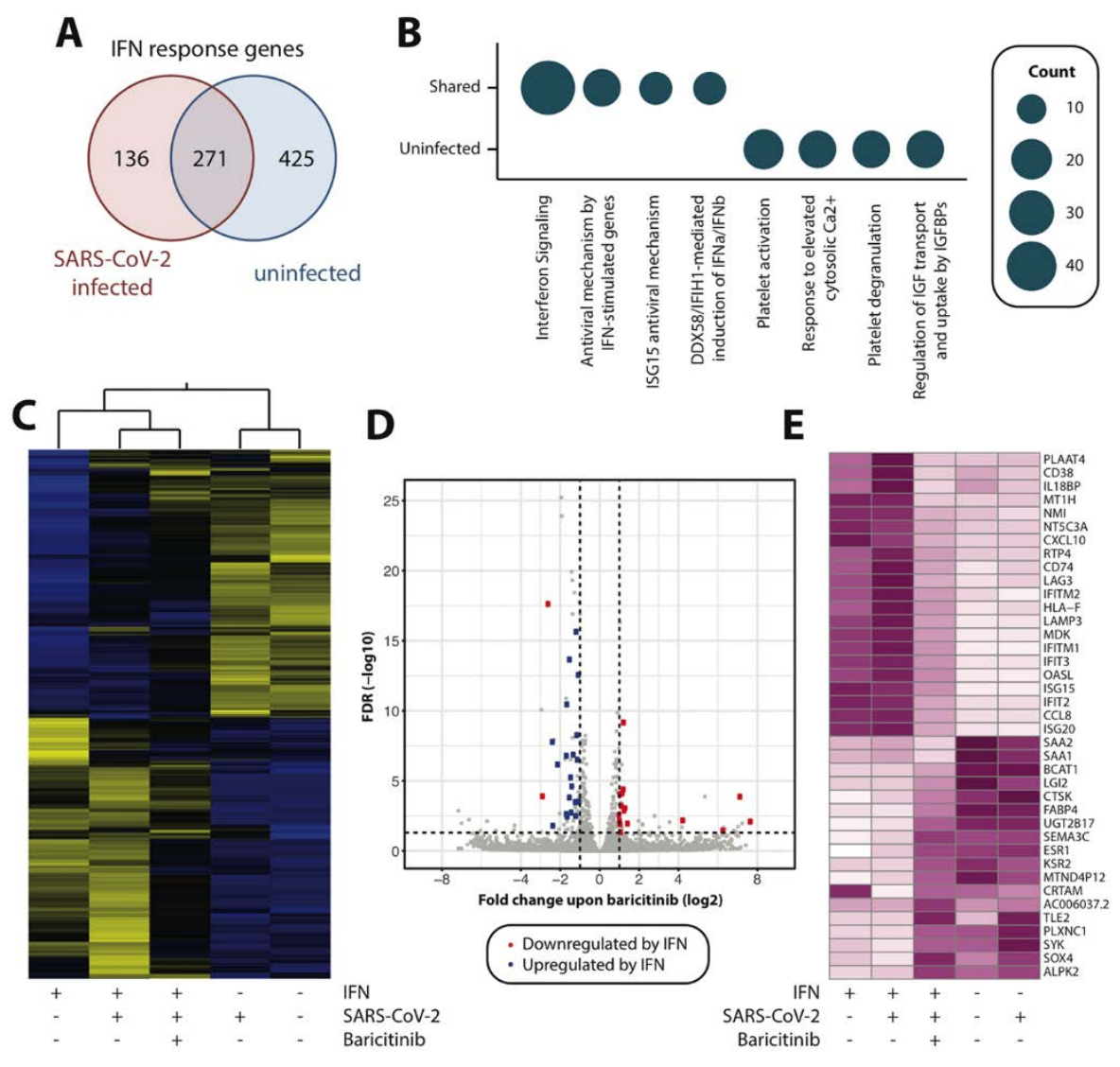

Fig. 4. Baricitinib reverses IFN-mediated gene expression signature alterations. A, Venn diagram depicting the overlap of differentially expressed genes upon IFN $\alpha 2(10 \mathrm{ng} / \mathrm{ml})$ in SARS-CoV-2 infected and uninfected liver spheroids. B, Circle plots illustrating significantly deregulated genes falling into specific Reactome terminologies in infected and noninfected samples $(F D R<0.05)$. Circle diameter is indicative for the number of genes per category. C, Heatmap representation of IFN-responsive genes $(n=832)$. Zscores of normalized TPMs are plotted (purple: high, white: low). D, Volcano plot showing the differentially expressed genes in all infected samples upon treatment with baricitinib. Blue and red dots indicate genes that are significantly up- and down-regulated upon IFN treatment. Note that with the exception of SAA1/2, baricitinib results in inverse changes to gene expression compared to IFN, thus ameliorating IFN-induced gene expression alterations. $\mathrm{E}$, Heatmap visualization of genes for which significant effects on gene expression were detected for baricitinib and IFN. 

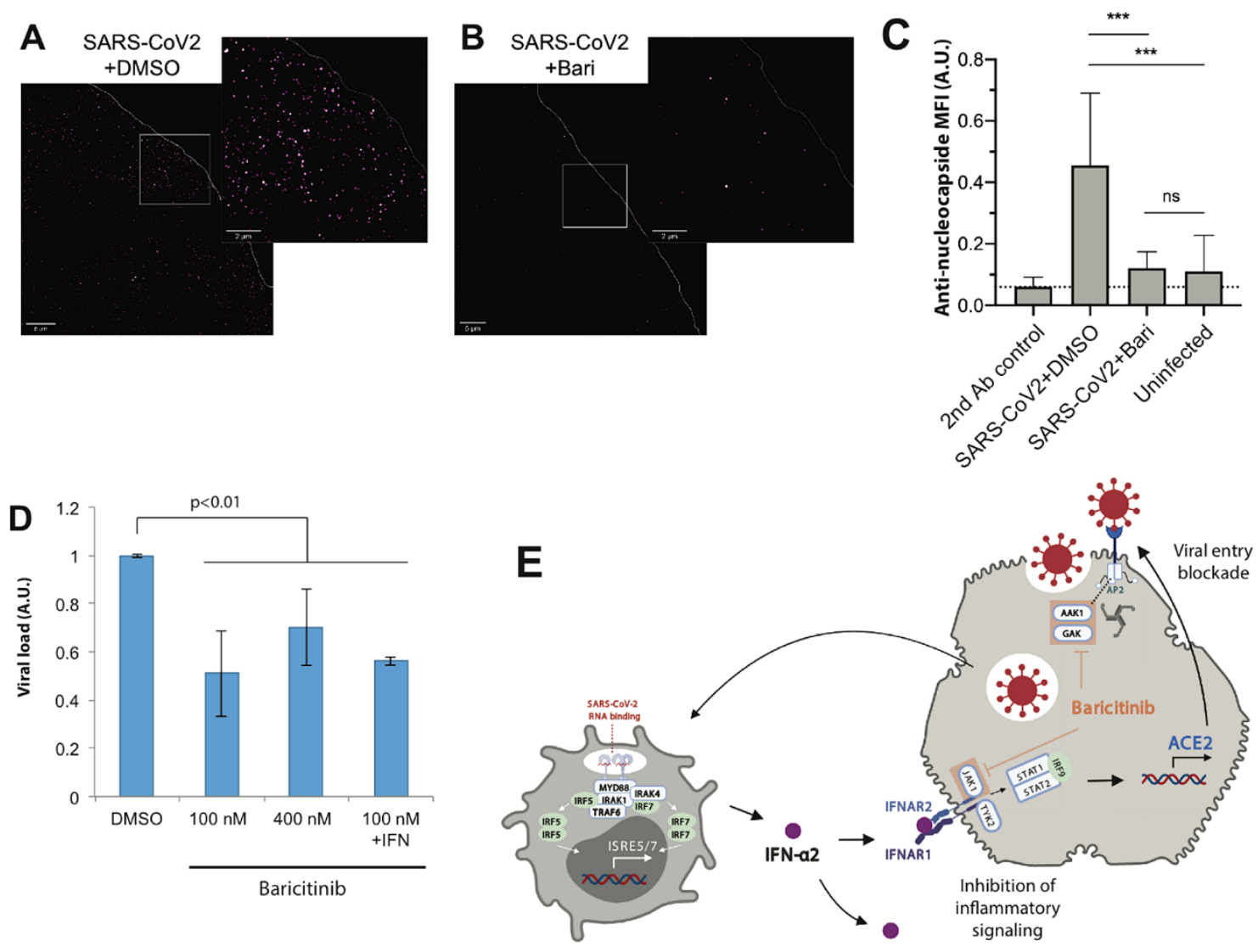

Fig. 5. Baricitinib blocks viral entry of SARS-CoV-2. Super-resolution dSTORM microscopy of short-term (4h) infected liver spheroids stained for nucleocapside treated with vehicle control (A) or baricitinib (100 nM; B). C, Relative mean fluorescence intensities (MFIs) for $20 \times 20 \mu \mathrm{m}$ regions of infected and treated organoids, and secondary antibody-only controls; five regions per 3D tissue culture. Bars are mean \pm S.D.; *** $\mathrm{p}<0.001$ two-tailed student $t$ test. D, qPCR analysis of viral load in organotypic primary human liver culture following short-term (4 hours) infections corroborates inhibition of viral entry. E, Suggested mechanism of dual baricitinib anti-viral action on viral entry and inflammatory signaling. Baricitinib inhibits on viral entry by inhibition of the numb associated kinases AAK1 and GAK. In addition, baricitinib blocks inflammatory JAK/STAT signaling, resulting in reduced expression of the interferon target gene and SARS-CoV-2 receptor ACE2. A plasmacytoid dendritic cell is shown on the left, a hepatocyte on the right. 
Table 1. Characteristics of patients receiving or not receiving baricitinib in the un-matched and matched study population from the University of Pisa (Italy).

\begin{tabular}{|c|c|c|c|}
\hline & $\begin{array}{l}\text { Baricitinib group } \\
(n=37)\end{array}$ & $\begin{array}{l}\text { Control } \\
\text { group } \\
(n=142)\end{array}$ & $\begin{array}{l}\text { PS matched } \\
\text { control group } \\
(n=37)\end{array}$ \\
\hline Age & $66.0(48.0-84.0) \dagger$ & $76.5(62.5-83) \dagger$ & $65(40-90)$ \\
\hline Male sex & $27(73)$ & $95(66.9)$ & $26(70.3)$ \\
\hline $\begin{array}{l}\text { Interval between symptom onset and } \\
\text { admission }\end{array}$ & $6(3.5-9)$ & $7(3-8)$ & $7(4-7.5)$ \\
\hline \multicolumn{4}{|l|}{ Coexisting conditions } \\
\hline Hypertension & $16(43.2)$ & $79(55.9)$ & $18(48.6)$ \\
\hline Cardiovascular disease & $9(24.3)$ & $56(39.4)$ & $6(16.2)$ \\
\hline Solid cancer & $6(16.2)$ & $22(15.5)$ & 9 (24.3) \\
\hline Diabetes & $7(18.9)$ & $32(22.5)$ & $8(21.6)$ \\
\hline COPD & $1(2.7)^{*}$ & $27(19.0)^{*}$ & $0(0.0)$ \\
\hline Chronic kidney failure & $2(5.4)$ & $16(11.3)$ & $1(2.7)$ \\
\hline Charlson Comorbidity Index & $2(0-4)$ & $2(1-5)$ & $1(0-6)$ \\
\hline \multicolumn{4}{|l|}{ Medications at baseline } \\
\hline ACE inhibitor or ARB & $9(24.3)$ & $43(30.4)$ & $9(24.3)$ \\
\hline Direct oral anticoagulant or warfarin & $5(13.5)$ & $24(16.9)$ & $1(2.7)$ \\
\hline SOFA score & $3(1-5)$ & $3(2-4)$ & $3(2-4)$ \\
\hline Baseline $\mathrm{PaO}_{2} / \mathrm{FiO}_{2}$ & $242(143-341)$ & $254(200-298)$ & $252(169-335)$ \\
\hline Non-invasive mechanical ventilation & $17(45.9) \ddagger$ & $19(13.4) \ddagger$ & $13(35.1)$ \\
\hline \multicolumn{4}{|l|}{ Baseline laboratory tests } \\
\hline C-reactive protein, $\mathrm{mg} / \mathrm{dl}$ & $5.7(0.0-18.0)$ & $8.3(3.7-16.1)$ & $11.2(0.0-25.4)$ \\
\hline Lymphocyte count & $1010(400-1620)$ & $830(580-1160)$ & $740(145-1335)$ \\
\hline Alanine aminotransferase, $\mathrm{U} / \mathrm{L}$ & $39(13-65)$ & $25(16-45)$ & $28(0-58)$ \\
\hline Aspartate aminotransferase, U/L & $43(12-74)$ & $33(24-50)$ & $32(10-54)$ \\
\hline$A L T>3 \times U L N$ & $1(2.7 \%)$ & $8(5.6 \%)$ & $1(2.7 \%)$ \\
\hline AST $>3 \times$ ULN & $1(2.7 \%)$ & $11(7.7 \%)$ & $2(5.4 \%)$ \\
\hline Total bilirubin, mg/dL & $0.51(0.31-0.71)$ & $0.49(0.35-0.77)$ & $0.48(0.08-0.88)$ \\
\hline \multicolumn{4}{|l|}{ Concomitant treatment } \\
\hline Hydroxychloroquine & $34(91.9)^{*}$ & $102(71.8)^{*}$ & $34(91.9)$ \\
\hline Other antibiotics & $33(89.2)$ & $109(76.8)$ & $34(91.9)$ \\
\hline Proteases inhibitors & $30(81.1)^{*}$ & $89(62.7)^{*}$ & $29(78.4)$ \\
\hline LMWH (enoxaparin) & $36(97.3) \ddagger$ & $98(69) \ddagger$ & $36(97.3)$ \\
\hline Steroids & $27(73.0) \dagger$ & $65(45.8) \dagger$ & $28(75.7)$ \\
\hline Primary outcome & $5(13.5) \ddagger$ & $66(46.5) \ddagger$ & $13(35.1)^{*}$ \\
\hline Invasive mechanical ventilation & $4(10.8)$ & $19(13.4)$ & $9(24.3)$ \\
\hline Died without intubation & $1(2.7)$ & $47(33.1)$ & $4(5.4)$ \\
\hline
\end{tabular}

All data are medians with the interquartile range, or number of participants (\%). LMWH: Low Molecular Weight Heparin. PS: Propensity score, ULN: upper limit of normal; * $p<0.05 ; \dagger p<0.01 ; \ddagger p<0.001$. 
Table 2. Characteristics of patients receiving or not receiving baricitinib in the un-matched and matched study population from the Albacete Hospital (Spain).

\begin{tabular}{|c|c|c|c|}
\hline & $\begin{array}{l}\text { Baricitinib } \\
\text { group } \\
n=46\end{array}$ & $\begin{array}{l}\text { Control } \\
\text { group } \\
n=376\end{array}$ & $\begin{array}{l}\text { PS matched } \\
\text { control group } \\
(n=46)\end{array}$ \\
\hline Age & $80.9(5.8)$ & $82.7(6.3)$ & $80,6(6,3)$ \\
\hline Male sex & $30(65.2)$ & $201(53.5)$ & $30(65.2)$ \\
\hline Interval between symptom onset and admission & $7.4(5.2)$ & $7.3(4.9)$ & $7.3(5.1)$ \\
\hline \multicolumn{4}{|l|}{ Coexisting conditions } \\
\hline Hypertension & $34(73.9)$ & $296(78.7)$ & $35(76.1)$ \\
\hline Cardiovascular disease & $18(39.1)$ & $167(44.4)$ & $15(32.6)$ \\
\hline Solid cancer & $2(4.3)$ & $20(5.3)$ & $1(2.2)$ \\
\hline Diabetes & $21(45.7)$ & $139(37.0)$ & $14(30.4)$ \\
\hline COPD & $11(23.9)$ & $84(22.3)$ & $12(26.1)$ \\
\hline Chronic kidney failure & $5(10.9)$ & $64(17.0)$ & $6(13.0)$ \\
\hline Charlson Comorbidity Index & $2.9(2.3)$ & $2.0(1.9)$ & $3.2(2.8)$ \\
\hline \multicolumn{4}{|l|}{ Medications at baseline } \\
\hline ACE inhibitor or ARB & $24(52.2)$ & $196(52.3)$ & $26(56.5)$ \\
\hline Direct oral anticoagulant or warfarin & $8(17.4)$ & $65(17.3)$ & $4(8.7)$ \\
\hline Antiaggregants & $14(30.4)$ & $121(32.2)$ & $15(32.6)$ \\
\hline Statins & $23(50.0)$ & $158(42.0)$ & $21(45.7)$ \\
\hline Insulin & $9(19.6)$ & $42(11.2)$ & $4(4.3)$ \\
\hline Oral hypoglycemic agents & $15(32.6)$ & $109(29.0)$ & $13(28.3)$ \\
\hline Antidepressants & $10(21.7)$ & $123(32.7)$ & $11(23.9)$ \\
\hline Inhaled therapy for COPD & $12(26.1)$ & $95(25.3)$ & $15(32.6)$ \\
\hline Baseline $\mathrm{PaO}_{2} / \mathrm{FiO}_{2}$ & $284(109)$ & $280(107)$ & $282(96)$ \\
\hline \multicolumn{4}{|l|}{ Baseline laboratory tests } \\
\hline $\mathrm{D}$-dimer $(\mathrm{mcg} / \mathrm{L})$ & 6944 (18052) & $6182(26894)$ & $5443(16872)$ \\
\hline Lactate dehydrogenase (U/L) & $387(136)$ & $372(288)$ & $370(166)$ \\
\hline C-reactive protein (mg/L) & $147.2(98.6)$ & $137.6(118.0)$ & $141.8(145.8)$ \\
\hline Ferritin (ng/mL) & $1357(1094) \dagger$ & $878(975) \dagger$ & $1039(927)$ \\
\hline Leucocyte count (/mcL) & $9414(4790)$ & 8986 (4711) & $7690(3675)$ \\
\hline Lymphocyte count (/mcL) & $987(905)$ & $967(777)$ & $934(517)$ \\
\hline Hemoglobin (g/dL) & $13.7(2.1)$ & $13.2(2.1)$ & $13.7(3.2)$ \\
\hline Fibrinogen $(\mathrm{mg} / \mathrm{dL})$ & $395(78)$ & $378(175)$ & $375(70)$ \\
\hline Creatinin (mg/dL) & $1.2(0.5)$ & $1.3(0.91)$ & $1.1(0.5)$ \\
\hline Aspartate aminotransferase $(\mathrm{U} / \mathrm{L})$ & $35.5(23.4)$ & $41.4(40.3)$ & $40(46)$ \\
\hline Gamma- glutamyltransferase (U/L) & $63.3(49.5)$ & $54.2(74.3)$ & $65.5(119.2)$ \\
\hline $\operatorname{ALT}(U / L)$ & $33.8(25.3)$ & $30.8(57.3)$ & $31.0(25.5)$ \\
\hline $\operatorname{ALT}(U / L)$ post treatment, at discharge & $47.5(45.8)$ & - & 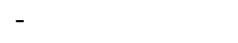 \\
\hline ALT > 2XULN post treatment, at discharge & $5(9.1)$ & - & - \\
\hline ALT > 3xULN post treatment, at discharge & $3(5.5)$ & - & - \\
\hline \multicolumn{4}{|l|}{ Chest X-Ray } \\
\hline Interstitial pattern & $46(100)$ & $345(93.0)$ & $44(95.7)$ \\
\hline Opacities & $38(82.6)^{*}$ & $233(63.7)^{*}$ & $32(69.6)$ \\
\hline Severity Score & $3.4(2.1) \dagger$ & $2.2(2.2) \dagger$ & $2.4(2.1)$ \\
\hline
\end{tabular}


Concomitant treatment

Hydroxychloroquine

Antibiotics

Lopinavir/Ritonavir

LMWH (enoxaparin)

Glucocorticoids

Anakinra

$\begin{array}{lll}45(97.8)^{*} & 321(85.4)^{*} & 46(100) \\ 46(100) & 365(97.1) & 45(97.8) \\ 39(84.8) & 288(76.8) & 42(91.3) \\ 46(100) \dagger & 322(85.6) \dagger & 46(100) \\ 44(95.7) \ddagger & 266(70.7) \ddagger & 42(91.3) \\ 18(39.1) \ddagger & 29(7.7) \ddagger & 10(21.7) \\ 9(19.6) \dagger & 157(41.8) \dagger & 16(34.8)\end{array}$

Primary outcome (mortality or IMV)

$9(19.6) \dagger$

$157(41.8) \dagger$

$16(34.8)$

Legend: COPD: Chronic Obstructive Pulmonary Disease. ALT: Alanine aminotransferase. LMWH: Low Molecular Weight Heparin. IMV: Invasive mechanical ventilation. ULN: upper limit of normal. All data are means (SD) or number of participants $(\%){ }^{*} p<0.05 ; \dagger p<0.01 ; \ddagger p<0.001$. 
Table 3. Common characteristics of patients receiving or not receiving baricitinib in the propensity score matched populations from the University of Pisa and the Albacete Hospital.

\begin{tabular}{lll}
\hline Age & $\begin{array}{l}\text { Baricitinib group } \\
(\mathrm{n}=83)\end{array}$ & $\begin{array}{l}\text { PS control group } \\
(\mathrm{n}=83)\end{array}$ \\
Male sex & $74.0(12.5)$ & $74.1(13.6)$ \\
Coexisting conditions & $43(51.8)$ & $42(50.6)$ \\
Hypertension & $50(60.2)$ & $53(63.9)$ \\
Cardiovascular disease & $27(32.5)$ & $21(25.3)$ \\
Solid cancer & $8(9.6)$ & $10(12.0)$ \\
Diabetes & $28(33.7)$ & $22(26.5)$ \\
COPD & $12(14.5)$ & $12(14.5)$ \\
Chronic kidney failure & $7(8.4)$ & $7(8.4)$ \\
Charlson Comorbidity Index & $2.7(2.3)$ & $2.8(2.7)$ \\
Medications at baseline & & \\
ACE inhibitor or ARB & $33(39.8)$ & $35(42.2)$ \\
Baseline PaO $/$ FiO & & $266(86)$ \\
Baseline laboratory tests & $268(101)$ & \\
C-reactive protein (mg/L) & & $82.2(123.9)$ \\
Lymphocyte count $(/ \mathrm{mcL})$ & $86.0(100.6)$ & $40(46)$ \\
ALT (U/L) & $1052(831)$ & $34.6(29.9)$ \\
Concomitant treatment & $38.7(26.5)$ & \\
Hydroxychloroquine & & $80(96.4)$ \\
Antibiotics & $79(95.2)$ & $79(95.2)$ \\
Lopinavir/Ritonavir & $79(95.2)$ & $71(85.5)$ \\
Low Molecular Weight Heparin & $69(83.1)$ & $82(98.8)$ \\
Glucocorticoids & $82(98.8)$ & $70(84.3)$ \\
Primary outcome & $71(85.5)$ & $29(34.9) \dagger$ \\
Time to outcome & $14(16.9) \dagger$ & $13.1(9.7) \ddagger$ \\
\hline Propensity scorematching. COPD: & $19.9(9.1) \ddagger$ & \\
\hline
\end{tabular}

PS: Propensity score matching. COPD: Chronic Obstructive Pulmonary Disease. ALT: Alanine aminotransferase. All data are means (SD) or number of participants (\%). $\dagger p<0.01 ; \ddagger p<0.001$. 
Table 4. Multivariate Cox-regression analyses for the primary outcome in the propensity score matched populations from the University of Pisa and the Albacete Hospital. Selection bias was addressed by propensity score analysis. Briefly, this is a two-phase technique used to estimate a treatment effect in comparative groups selected by non-random means. In the first phase of a propensity score analysis, variables that influence selection to group assignment are used to model the probability of receiving treatment (or of being in the reference group, in this case, the baricitinib group). The resulting probability is the propensity score. In the second phase, the propensity score is used to adjust for pre-existing group differences in the analysis of the relevant outcomes. There are several ways to use propensity scores such as stratification variables, matching patients based on their propensity score or their use as a weighting or adjustment variable during multivariate analysis. In the current study, each baricitinib patient was matched to a control patients based on comparable propensity scores. Assuming that all relevant covariates are included in the propensity score model, the group effect observed in a propensity score analysis represents an unbiased estimate of the true treatment effect.

\section{$\mathrm{HR}(95 \% \mathrm{Cl}) \quad p$}

\begin{tabular}{lll}
\hline Baricitinib & $0.29(0.15-0.58)$ & 0.0001 \\
Age & $1.01(0.98-1.04)$ & 0.470 \\
Male sex & $1.13(0.54-2.34)$ & 0.750 \\
Hypertension & $1.31(0.52-3.32)$ & 0.572 \\
Diabetes & $0.51(0.23-1.17)$ & 0.113 \\
Chronic Obstructive Lung Disease & $0.51(0.17-1.54)$ & 0.230 \\
Cardiovascular disease & $1.41(0.68-2.92)$ & 0.351 \\
Cronic kidney disease & $1.45(0.51-4.15)$ & 0.491 \\
Solid cancer & $1.18(0.49-2.87)$ & 0.709 \\
Charlson Comorbidity Index & $1.03(0.90-1.17)$ & 0.680 \\
Baseline PaO FiO $_{2}$ & $1.00(1.00-1.00)$ & 0.823 \\
Lymphocyte count $(/$ mcL) & $1.00(1.00-1.00)$ & 0.657 \\
Alanine aminotransferase & $1.01(1.00-1.03)$ & 0.026 \\
Hydroxychloroquine & $2.77(0.28-27.41)$ & 0.384 \\
Lopinavir/Ritonavir & $1.18(0.38-3.61)$ & 0.776 \\
Glucocorticoids & $1.79(0.60-5.34)$ & 0.299 \\
Low Molecular Weight Heparin & $0.10(0.01-1.33)$ & 0.081 \\
Antibiotics & $2.34(0.29-18.90)$ & 0.427 \\
\hline
\end{tabular}


Table 5. Baseline demographic, clinical, and laboratory characteristics of COVID-19 patients treated with either baricitinib or with standard COVID-19 therapy, and results at 2 weeks from the Hospital of Prato. Standard univariate statistical tests were performed to compare baricitinib-treated patients to age- and sexmatched controls. These consisted of the Mann-Whitney $U$ test for pairwise comparisons, the Wilcoxon-test for paired data and Fisher's exact test for categorical variables. Kaplan-Meier product-limit estimation and the log rank test were used to perform a survival analysis between groups. A dose of $4 \mathrm{mg}$ daily baricitinib was given for 14 days.

\begin{tabular}{|c|c|c|c|}
\hline $\begin{array}{l}\text { Features at baseline (all patients received } \\
\text { hydroxychloroquine and lopinavir/ri- } \\
\text { tonavir) }\end{array}$ & Baricitinib group & Control group* & $P$ value \\
\hline Patient number, N (\%) & $23(100)$ & $18(100)$ & \\
\hline Male/female, N (\%) & $20 / 3(87 / 13)$ & $14 / 4(78 / 22)$ & 0.679 \\
\hline Age years, median (IQR) & $62.5(57.75-72.25)$ & $64.1(55.7-70.1)$ & 0.776 \\
\hline $\begin{array}{l}\text { Days interval from symptoms onset and } \\
\text { therapy starting }\end{array}$ & $6(4-6.25)$ & $5.5(4-5.25)$ & 0.924 \\
\hline Cough, N (\%) & $17(73.9)$ & $15(83.3)$ & 0.709 \\
\hline Dyspnea, N (\%) & $20(86.9)$ & $14(77.8)$ & 0.679 \\
\hline Sputum production, N (\%) & $7(30.4)$ & $9(50)$ & 0.334 \\
\hline Headache, N (\%) & $8(34.8)$ & $7(38.9)$ & 0.757 \\
\hline Diarrhea, N (\%) & $5(21.7)$ & $5(27.8)$ & 0.524 \\
\hline Ageusia/Anosmia, N (\%) & $9(39.1)$ & $8(44.4)$ & 0.860 \\
\hline Hypertension, N (\%) & $5(21.7)$ & $6(33.3)$ & 0.489 \\
\hline Diabetes, N (\%) & $6(26)$ & $4(22.2)$ & 1.000 \\
\hline COPD, $N(\%)$ & $5(21.7)$ & $4(22.2)$ & 1.000 \\
\hline CVD, N (\%) & $4(17.4)$ & $2 / 11.1)$ & 0.679 \\
\hline Malignancy, N (\%) & $1(4.3)$ & $1(5.5)$ & 1.000 \\
\hline Fever ${ }^{\circ} \mathrm{C}$ & $38(37.5-38.6)$ & $37.9(37.6-38.9)$ & 0.912 \\
\hline Respiratory rate $\mathrm{N} / \mathrm{min}$ & $18(16.5-23.2)$ & $21(18-24)$ & 0.524 \\
\hline $\mathrm{SpO} 2(\%)$ & $94(90-95.5)$ & $92(91-93)$ & 0.357 \\
\hline $\mathrm{PaO} 2 / \mathrm{FiO} 2$, median (IQR) & $293(199-296)$ & $271.4(264-283)$ & 0.356 \\
\hline Pulse rate, median (IQR) & $84(72.3-89.1)$ & $88(86-94.5)$ & 0.129 \\
\hline SBP mm/Hg, median (IQR) & $110(100-130)$ & $105(98-115.6)$ & 0.789 \\
\hline DBP mm/Hg, median (IQR) & $70(60-84)$ & $65.5(60-68.5)$ & 0.589 \\
\hline WBC $\left(\times 10^{9} / \mathrm{L}\right)$, median (IQR) & $7.6(5.7-10.4)$ & $7.9(7.1-8.6)$ & 0.757 \\
\hline Neutrophils $\left(\times 10^{9} / \mathrm{L}\right)$, median (IQR) & $6,3(4.2-7.8)$ & $7.1(6.4-8.1)$ & 0.224 \\
\hline Lymphocytes $\left(x 10^{9} / \mathrm{L}\right)$, median (IQR) & $0.6(0.5-1.1)$ & $0.72(0.6-0.8)$ & 0.524 \\
\hline Hemoglobin (g/L), median (IQR) & $116(102-133.2)$ & $127(108-136)$ & 0.565 \\
\hline Platelets $\left(\times 10^{9} / \mathrm{L}\right)$, median (IQR) & $207(174-232)$ & $368(340-415)$ & 0.002 \\
\hline $\operatorname{ALT}(\mathrm{IU} / \mathrm{L})$, median $(\mathrm{IQR}) \dagger$ & $27.6(22.7-53.1)$ & $44(36-50)$ & 0.176 \\
\hline AST (IU/L), median (IQR) & $31(25.2-47.3)$ & $44(34.7-48)$ & 0.235 \\
\hline ALT (IU/L) > upper normal limit N (\%) & $8(34.7)$ & $9(50)$ & 0.358 \\
\hline $\begin{array}{l}\text { ALT }(I U / L)>\text { upper normal limit, median } \\
(I Q R)\end{array}$ & $50(45.5-62.7)$ & $55(45-68)$ & 0.707 \\
\hline AST (IU/L) > upper normal limit N/\% & 10 & 11 & 0.350 \\
\hline $\begin{array}{l}\text { AST }(I U / L)>\text { upper normal limit, median } \\
(\text { IQR) }\end{array}$ & $51.5(44.5-76.5)$ & $67(55-80)$ & 0.302 \\
\hline Creatinine (mg/dl), median (IQR) & $1.0(0.9-1.3)$ & $1.1(0.9-1.2)$ & 0.789 \\
\hline CRP (mg/dl), median (IQR) & $9.12(5.9-16.5)$ & $4.3(1.5-5.2)$ & 0.001 \\
\hline Procalcitonin ng/ml, median (IQR) & $0.5(0.3-1.0)$ & $1.1(0.8-2.2)$ & 0.589 \\
\hline $\mathrm{IL}-6(\mathrm{pg} / \mathrm{ml})^{* *}$, median (IQR) & $29.2(7.1-39.4)$ & $24.2(5.2-27.6)$ & 0.189 \\
\hline MEWS, median (IQR) & $2(1-3.1)$ & $3(3-4)$ & 0.544 \\
\hline \multicolumn{4}{|l|}{ Results at 2 weeks post-therapy } \\
\hline ICU admission N (\%) & 0 & $5(33)$ & 0.011 \\
\hline Discharged, N (\%) & $18(78.2)$ & $1(5.5)$ & $<0.0001$ \\
\hline
\end{tabular}




\begin{tabular}{|c|c|c|c|}
\hline $\mathrm{SpO}_{2}$, median (IQR) & $97(94.8-98.1)$ & $92.4(85.5-93.2)$ & $<0.0001$ \\
\hline $\mathrm{PaO}_{2} / \mathrm{FiO}_{2}$ value, median (IQR) & $428.7(306.1-457)$ & $277.8(144-345)$ & 0.002 \\
\hline Lymphocytes $\times 10^{9} / \mathrm{L}$, median (IQR) & $1.3(1.2-1.9)$ & $0.8(0.6-0.9)$ & 0.019 \\
\hline CRP mg/dl, median (IQR) & $0.87(0.58-2.9)$ & $5.2(2.1-12.3)$ & $<0.0001$ \\
\hline $\mathrm{IL}-6(\mathrm{pg} / \mathrm{ml})^{* *}$, median $(\mathrm{IQR})$ & $6.1(3.2-7.4)$ & NA & NA \\
\hline ALT (IU/L), median (IQR) & $37(24.1-57.4$ & NA & NA \\
\hline AST (IU/L), median (IQR) & $55.4(28-64.3)$ & NA & NA \\
\hline
\end{tabular}

$\mathrm{SpO}_{2}=$ peripheral capillary oxygen saturation; $\mathrm{PaO}_{2} / \mathrm{FiO}_{2}=$ ratio of arterial oxygen partial pressure to fractional inspired oxygen; $\mathrm{SBP}=$ systolic blood pressure; $\mathrm{DBP}=$ diastolic blood pressure; $\mathrm{WBC}=$ white blood cells;

AST=aspartate aminotransferase; ALT=alanine aminotransferase; IL-6=interleukin-6; MEWS=Modified Early Warning Score; COPD=chronic obstructive pulmonary disease; CVD=cardiovascular disease; NA=not applicable. *Standard therapy group: COVID-19 patients under standard respiratory therapy commenced antiretrovirals (Kaletra) and hydroxychloroquine before starting the therapy with baricitinib. $†$ Normal ALT and AST values: 10-40 IU/L. ${ }^{* *}$ II-6 normal value: $<7$ pg/ml. IQR: interquartile range; IU: international units. 